\title{
خصائص الإيقاع في بائيّة الخنساء
}

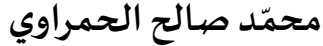 \\ المعهد العالي للعلوم الإنسانيّة- جامعة تونس المنار- تونس المعرائ \\ mohamed.hamraoui.beja@gmail.com
}

DOI: https://doi.org/10.31559/JALLS2020.2.2.3 r.r./T/V تاريخ قبول البحث

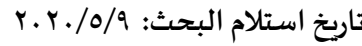

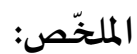

نبحث في هذا المقال عن خصائص الإيقاع في شعر النّسـاء من خلال بائيّة الخنساء. وقد عرّفنا في بدئه بهذا المفهوم نظريّا بالوقوف

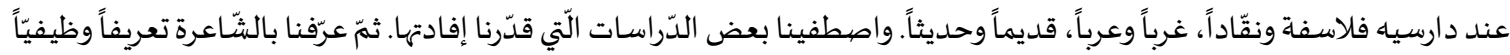

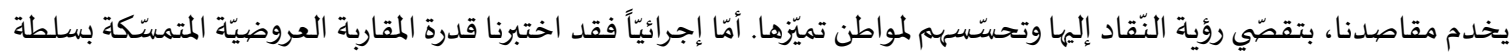

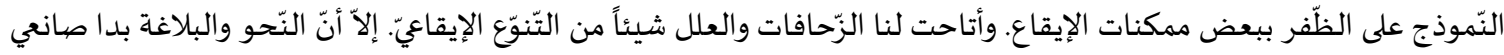

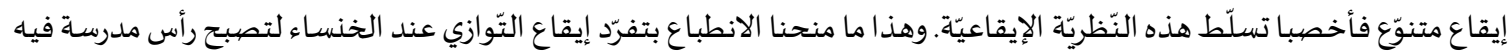

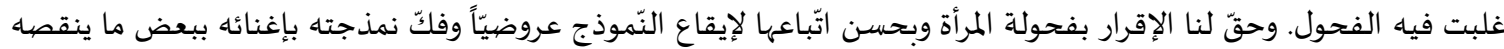

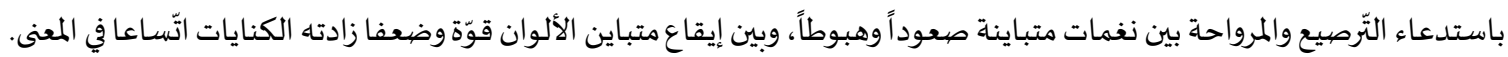

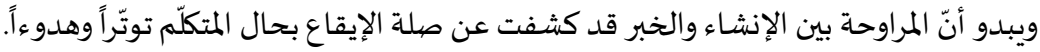

الكلمات المفتاحية: إيقاع؛ رويّ؛ قافية؛ مقطع؛ مطلع؛ نغمة صاعدة؛ نغمة مستوية، تمايز؛ تماثل؛ تفرّد؛ ثقل؛ خفّة؛ تكرار؛ تواز؛

اتّسـاع المعنى.

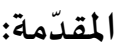

لم نر مفهوما تباينت في حدّه الآراء تباينها في ضبط حدّ الإيقاع. إذ مازال تعريفه عصيّا عن الإدراك، زئبقيّ الطّبع. وقد دلّ على هذا

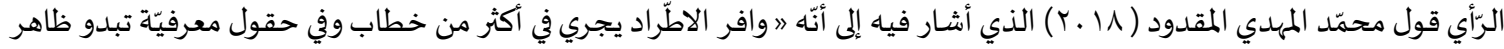
الأمر متباينة(...) ولكن هذه الوفرة في الحضور رافقها غالبا لبس في الدّلالة حتّى توشك أن يكون له في كلّ حقل معرفيّ حدّه الخاصّ. وهو ما سوّع لباحث معاصر أن يجمع مائة تعريف غربيّ كلّ واحد منها يلحّ على ناحية فيها يذهل عنها غيره، أو يرفع من درجة جانب فيه لم

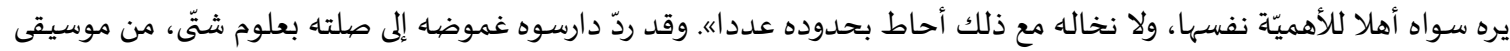

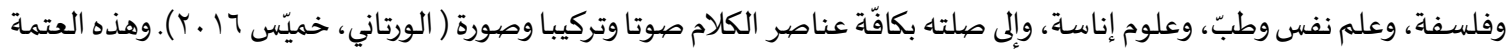

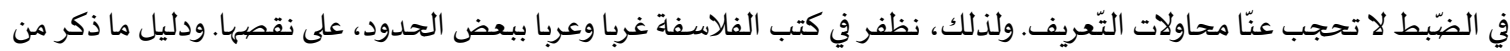

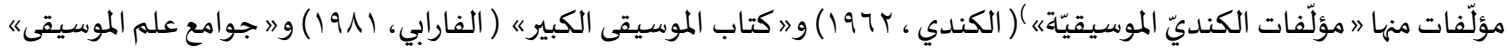

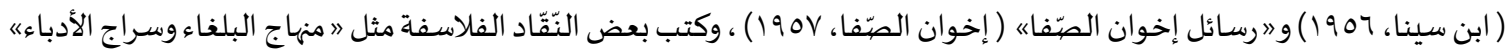

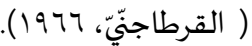

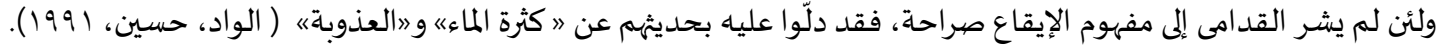

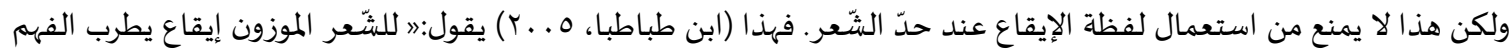
لصوابه ويرد عليه من حسن تركيبه واعتدال أجزائه. فإذا اجتمع للفهم مع صحّة وزن الشّعر صحّة المعنى وعذوبة اللّفظ، فصفيا

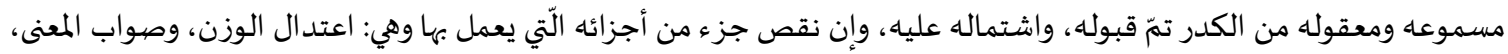
وحسن الألفاظ، كان إنكار الفهم إيّاه على قدر نقصان أجزائهس،. وهذا الذّكر للفظة الإيقاع يجد صداه عند آخرين. إذ أيّده

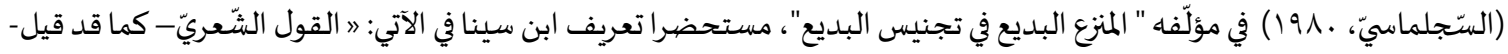




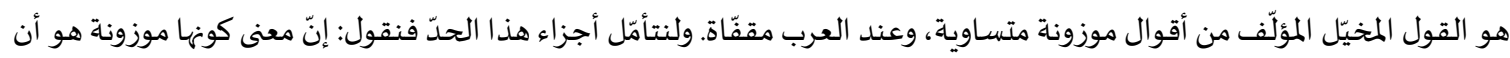

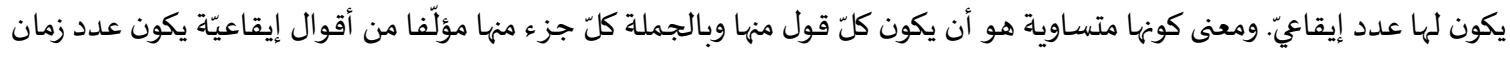

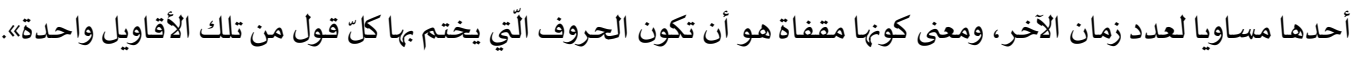

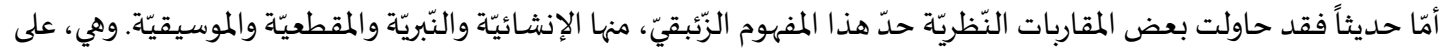

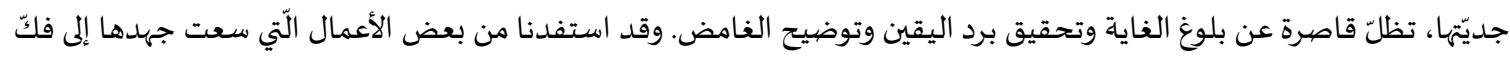

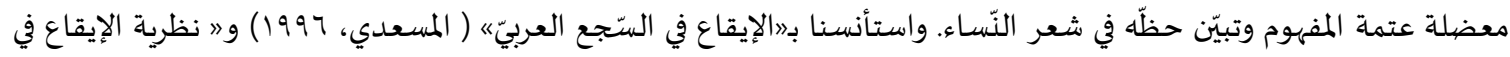

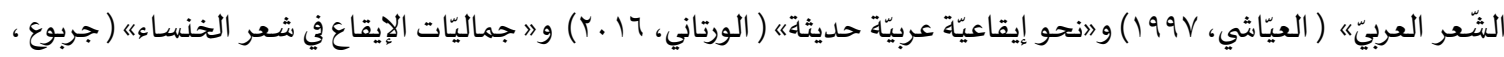

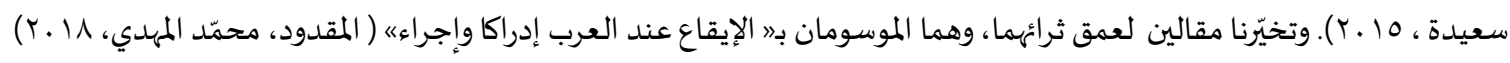

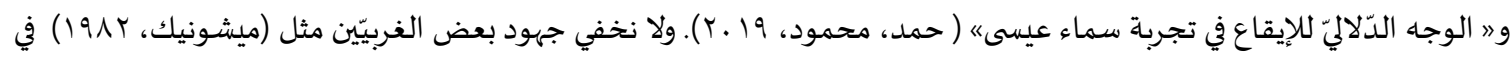

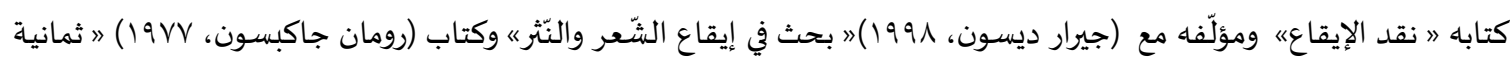

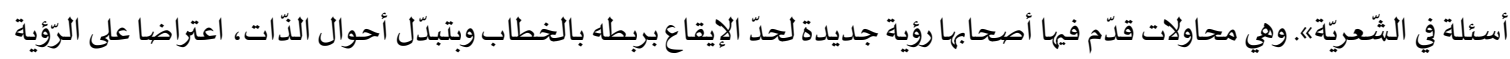

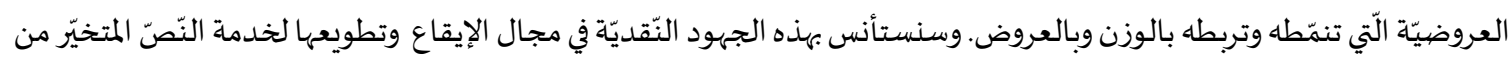

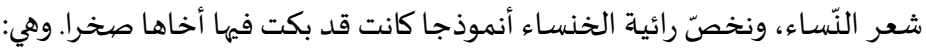

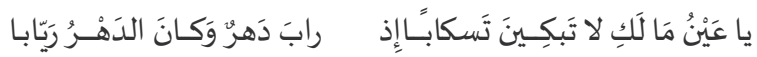

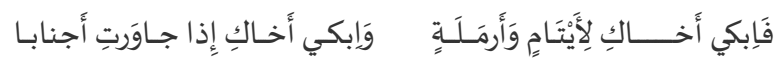

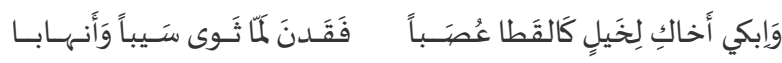

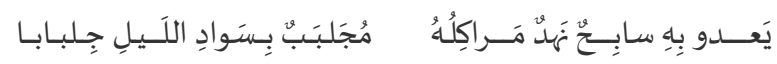

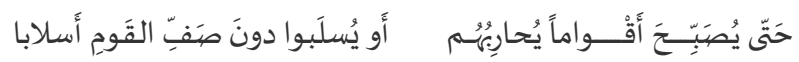

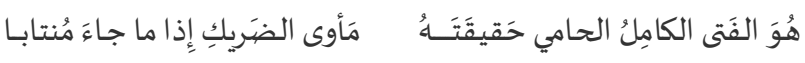

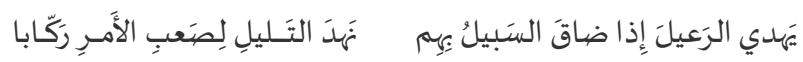

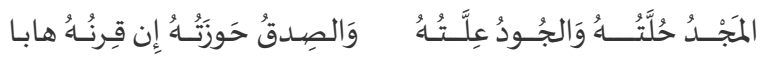

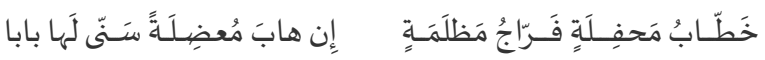

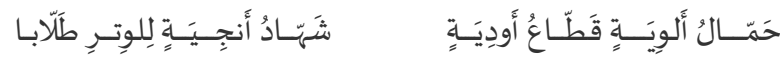

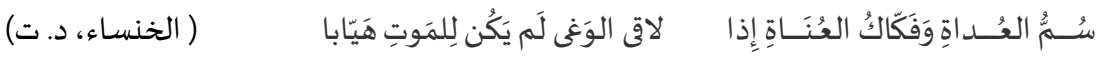

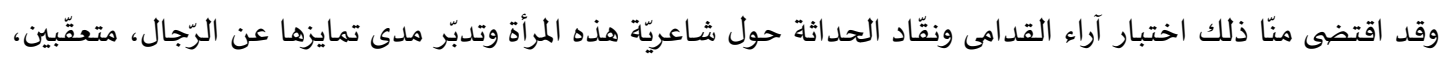

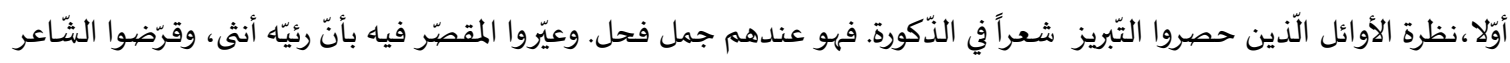

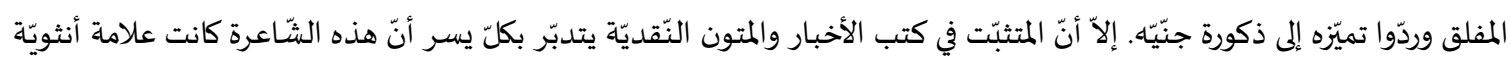

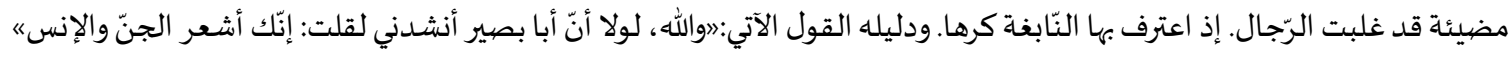

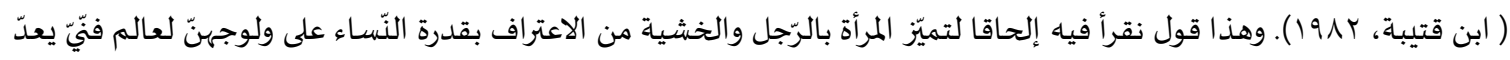

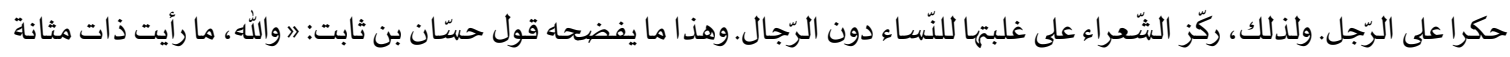

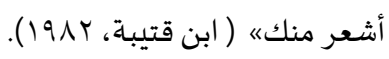

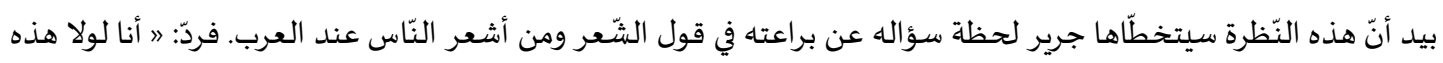

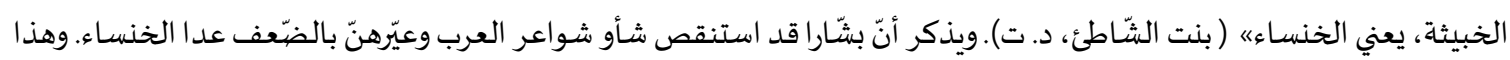

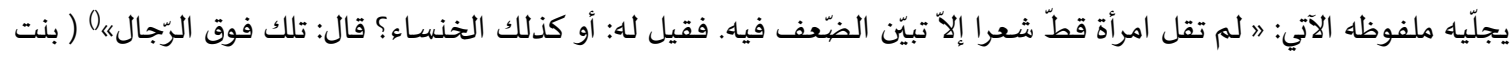

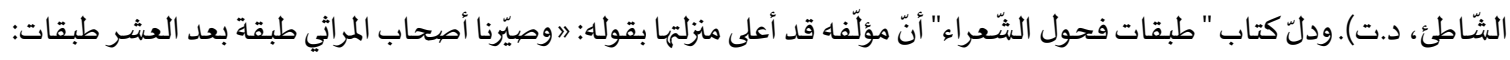

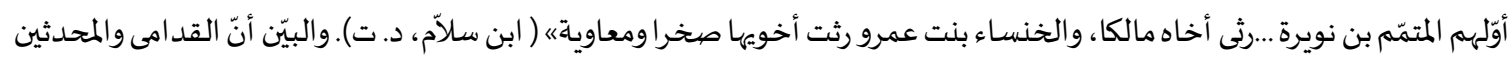

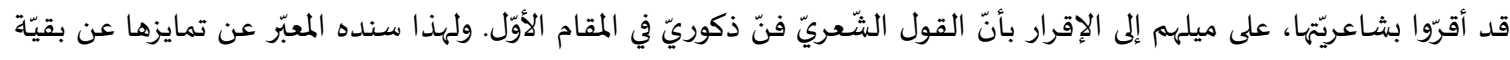

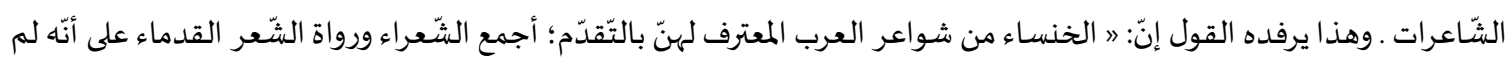

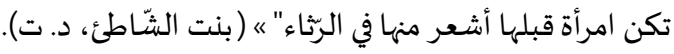




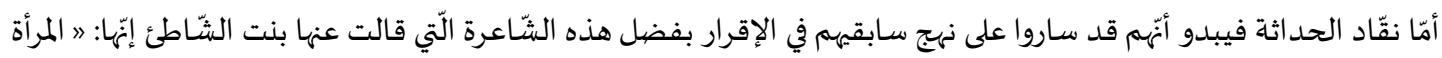

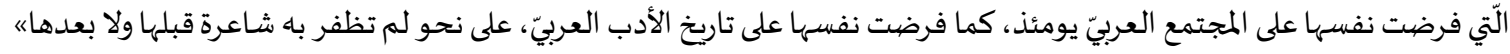

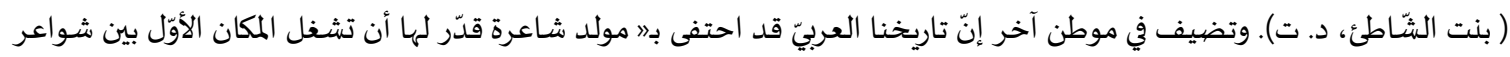

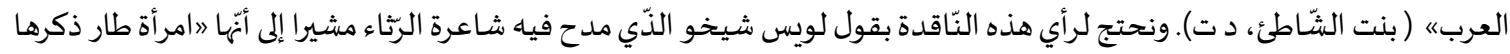

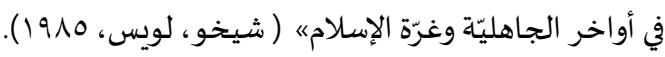

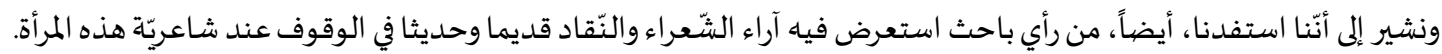

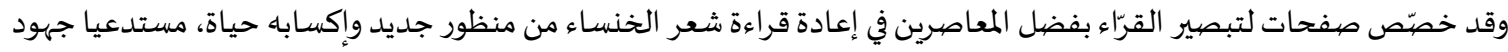

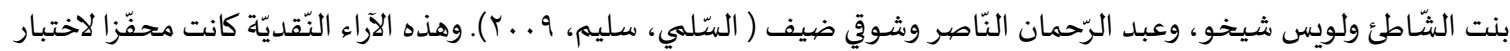

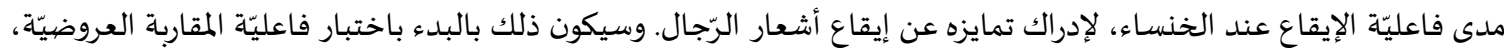

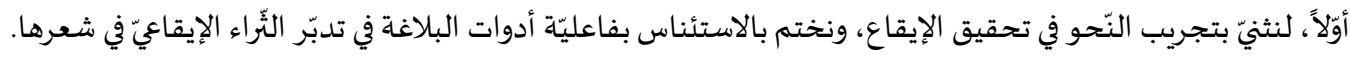

\section{فاعليّة المقاربة العروضيّة إيقاعيًّا:}

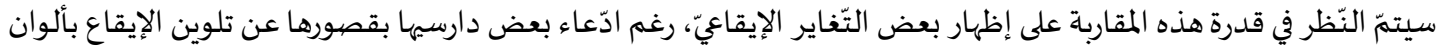

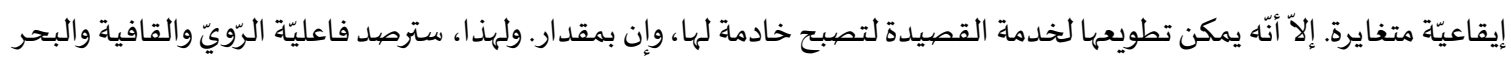

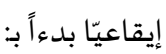

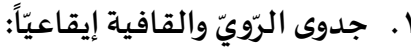

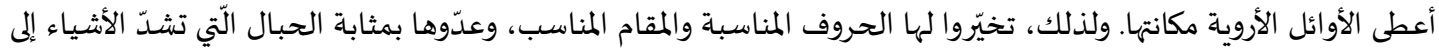

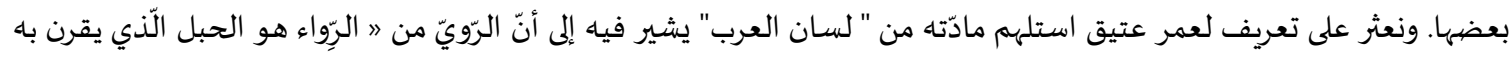

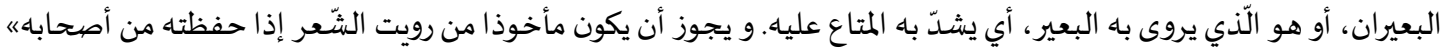

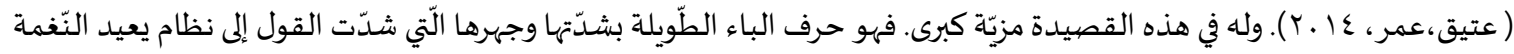

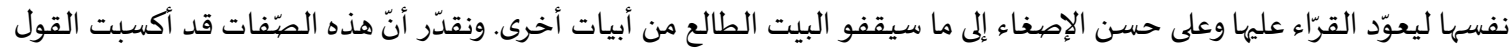

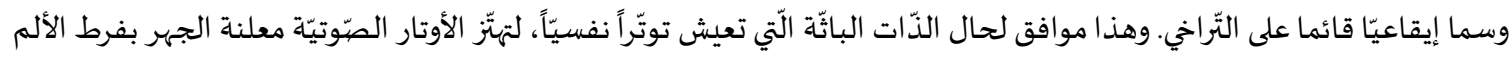

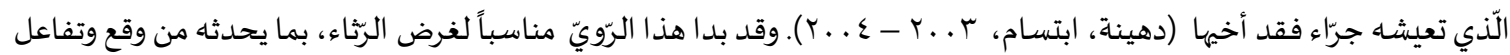

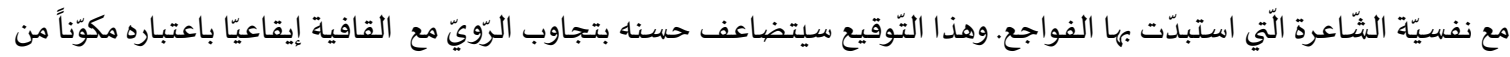

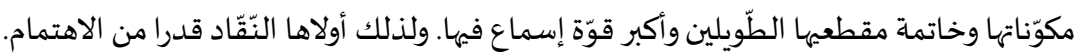

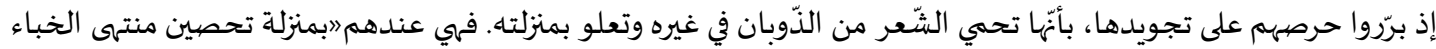

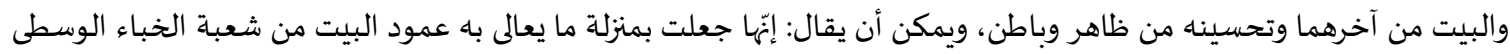

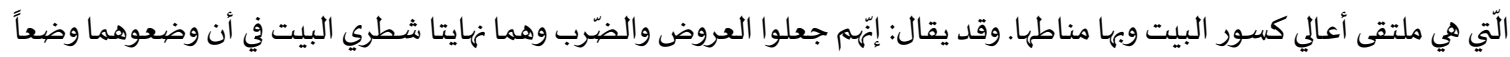

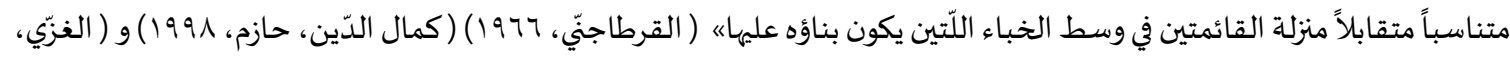

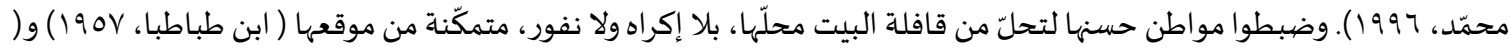

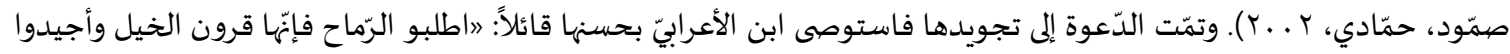

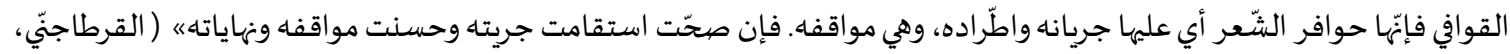

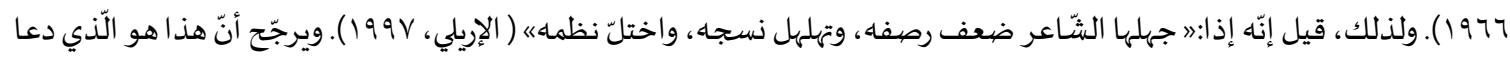

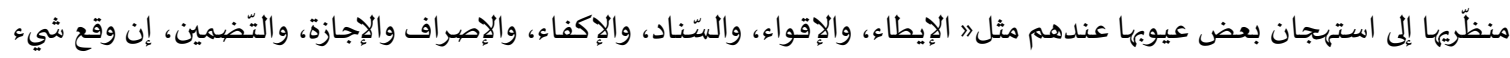

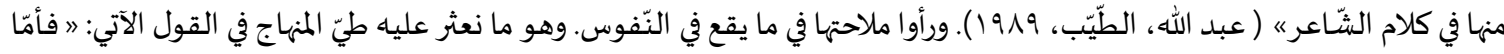

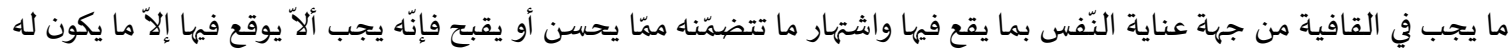

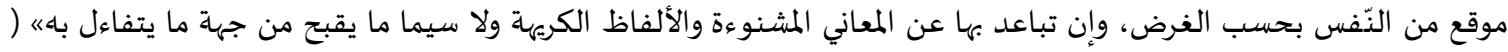

القرطاجنيّ، النيّ، (1977). ومن محاسنها في هذه القصيدة أن دلّت عليها الشّاعرة بالتّصريع، أولّاً الَّني يعتبر من محاسن الشّعر عند القدامى لأنّه شرط

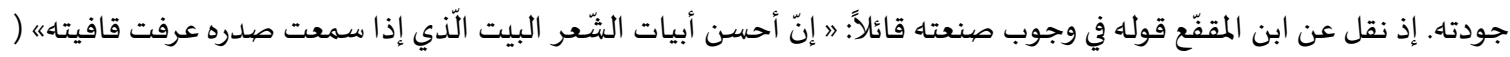

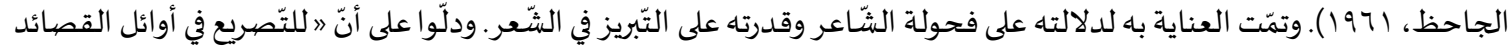


طلاوة وموقعاً في النّفس لاستدلالها به على قافية القصيدة قبل الانهاء إليها، ولمناسبة تحصل لها بازدواج صيغتي العروض والضّرب

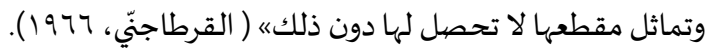
ويبدو أنّ أغلب الآراء التّتي تناولت القافية دحفِّزة على تقصّي إيقاعها واختبار وسوهها الإيقاعيّة في هذه الرَّائيّة باعتماد الجدول

\begin{tabular}{|c|c|c|c|c|}
\hline الوسم الإيقاعيّ & صفة الحرف ما قبل الرّوي & صهورتها الصيّوتيّة & القافية & 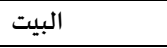 \\
\hline إيقاع أقلّ بطئاً ولكنّه قويّ & الياء (رخو، مجهور) & مقطعان طويلان & يابا & الأوَّلَّ \\
\hline 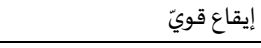 & النون (بين الشدّة والرخاوة، مجهور) & مقطعان طويلان & 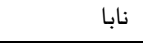 & 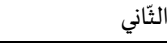 \\
\hline 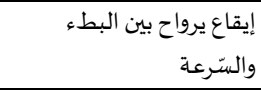 & الهاء (رخو، مهموس) & مقطعان طويلان & هابا & الثًّلث \\
\hline إيقاع بطيء جدّا وقويّ & الباء (شديد، مجهور) & مقطعان طويلان & بابا & الرّابع \\
\hline سابقاع أقلَّ بطئًاً قياساً إلى & اللالم ( بين الشُّدّة والرّخاوة، مجهور) & مقطعان طويلان & لابا ابا ابا & 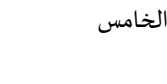 \\
\hline 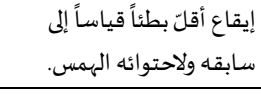 & التاء (شديد، مهموس) & مقطعان طويلان & تابا & ال السّادس \\
\hline إيقاع مماثل في وسمه لسابقه & الكاف (شديد، مهموس) & مقطعان طويلان & كابا & 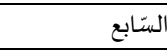 \\
\hline 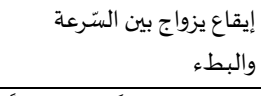 & الهاء (رخو، مهموس) & مقطعان طويلان & 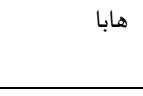 & الثَّامن \\
\hline لسابقاع بطيء جدّاً وقويّ قياساً & الباء(شديد، مهجور) & مقطعان طويلان & بابا & التَّاسع \\
\hline إيقاع أقلَّ بطئاً من سابقه & اللام ( بين الشدّة والرخاوة، مجهور) & مقطعان طويلان & لابا الابا & العاشر \\
\hline إيقاع أقلَ بطئًاً من سابقه & الياء (رخو، مجهور) & مقطعان طويلان & يابا & الحادي عشر \\
\hline
\end{tabular}

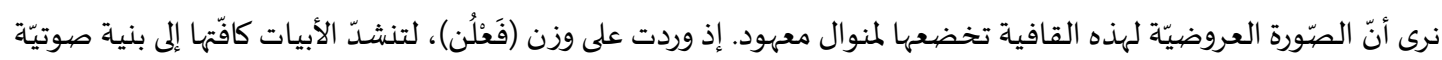

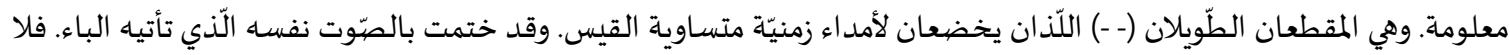

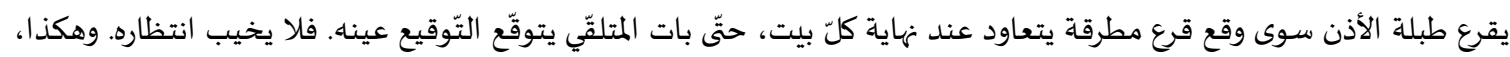

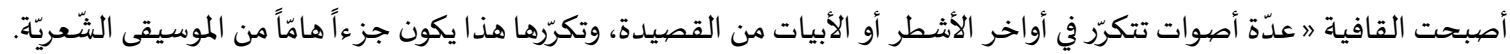

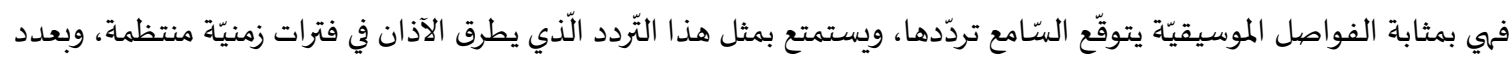

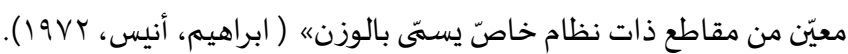

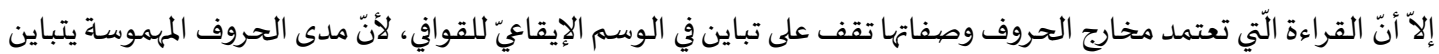

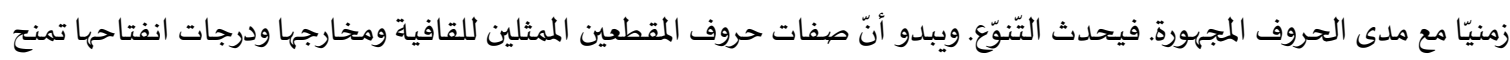

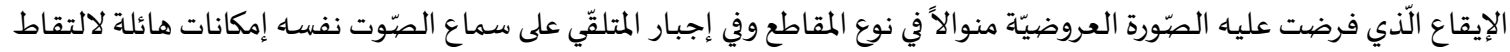

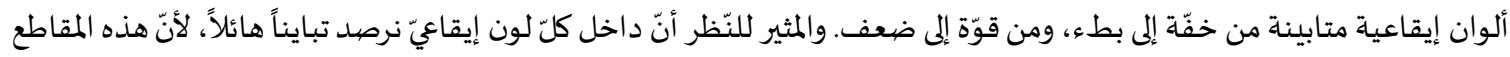

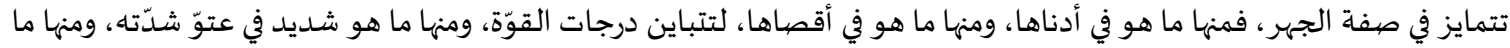

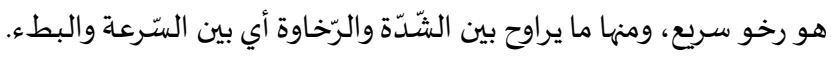

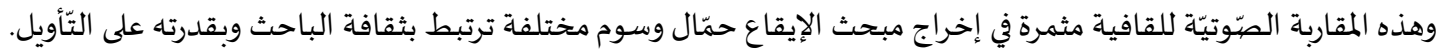

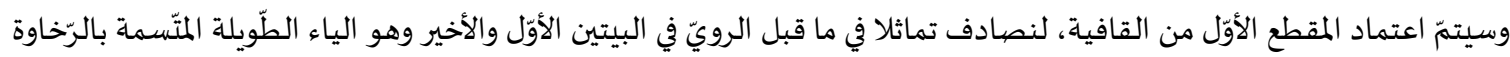

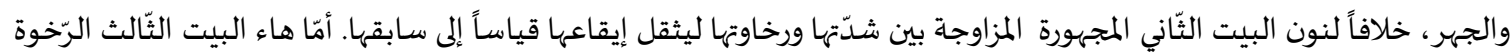

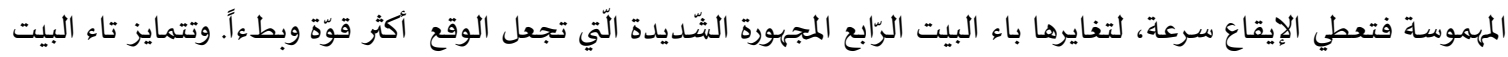

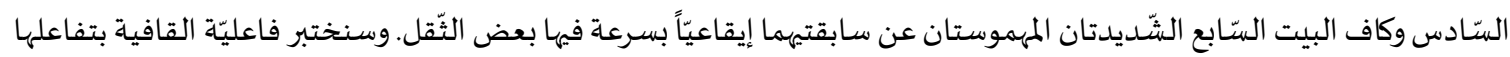

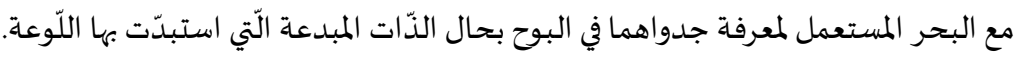

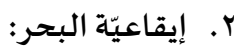

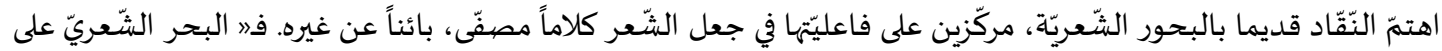

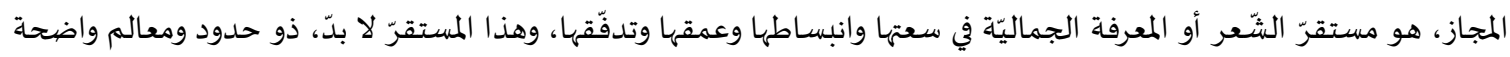

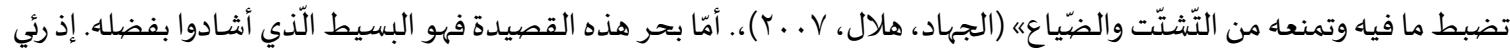

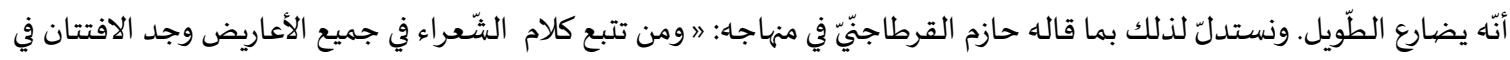




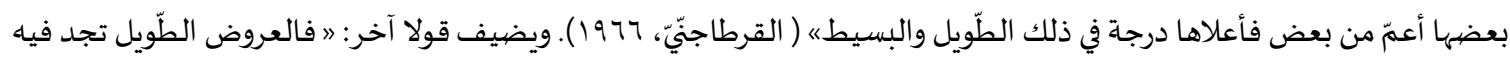

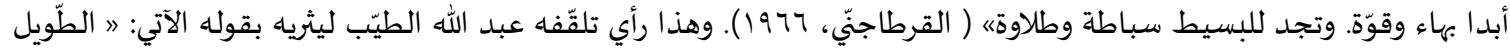

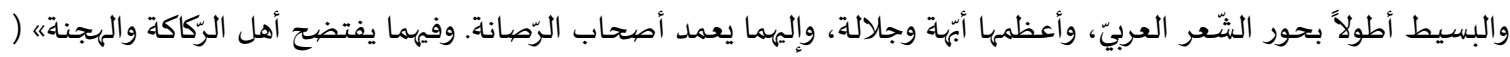

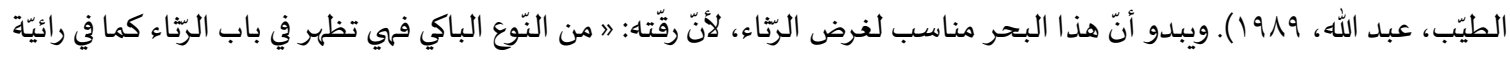

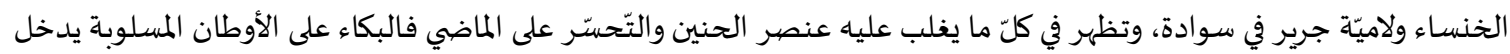

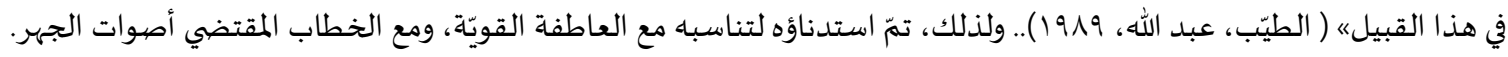

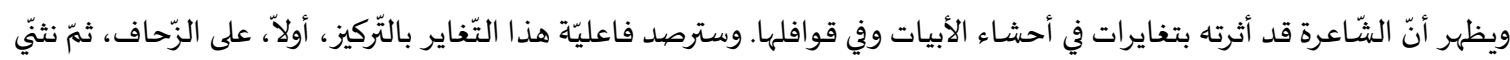

بالعلل.

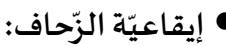

حدّد الخليل المواقع التّي يحسن فيها الزّحاف واستحسن منه ما ندر وقلَ. وسار سيره قدامة ابن جعفر التّني دعَّم هذه الرَّوَّة

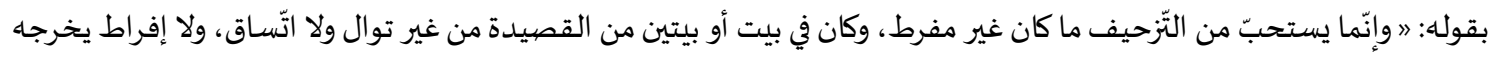

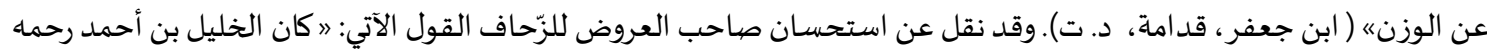

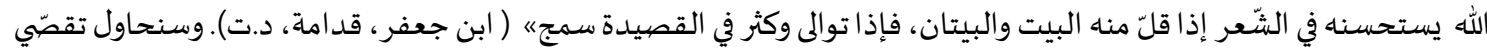

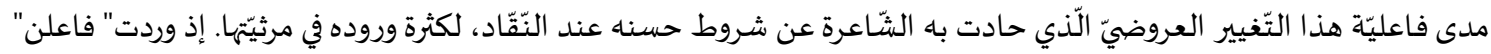

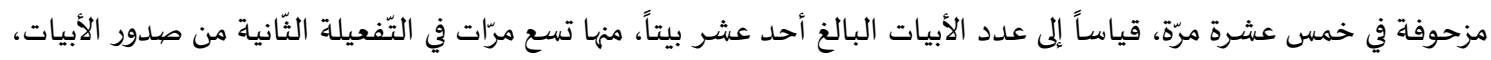

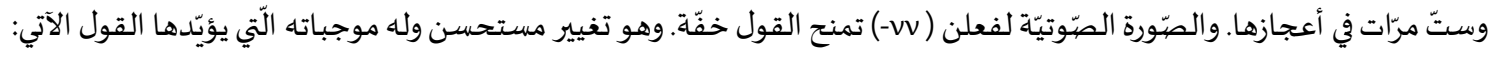

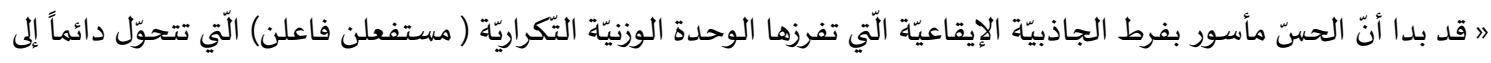

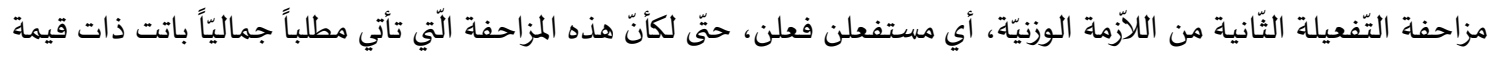

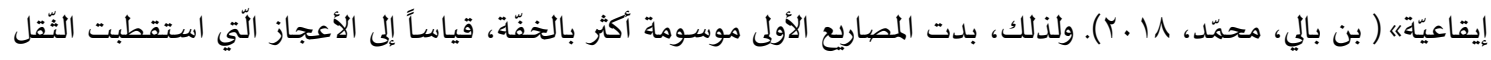

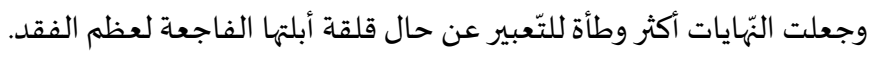

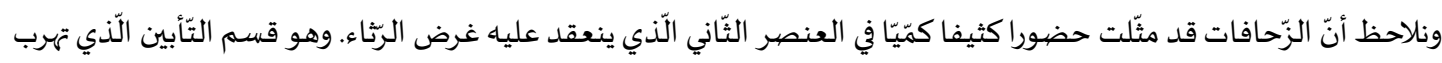

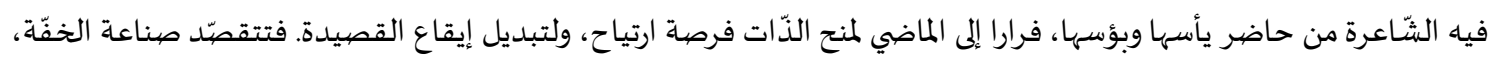

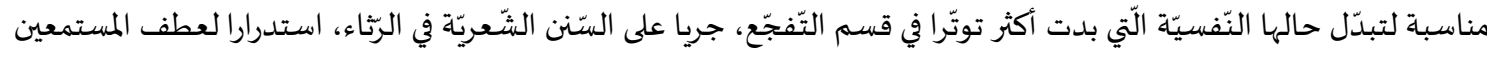

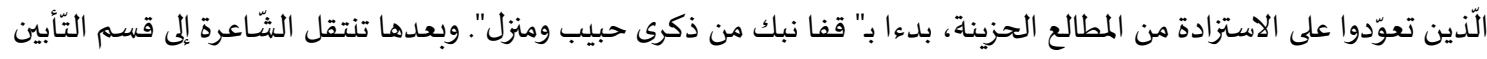

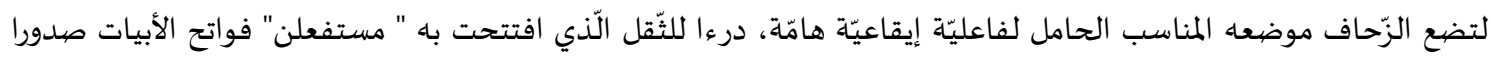

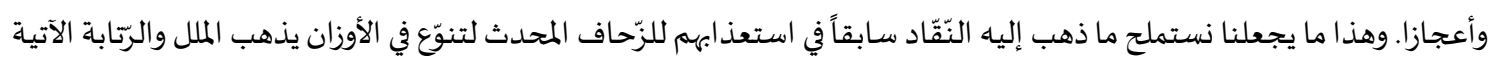

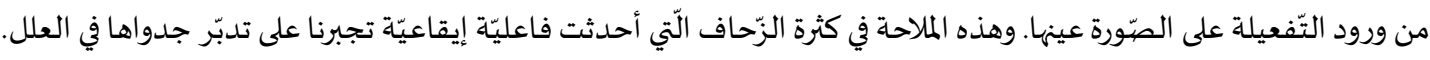

• (إيقاعيّة العلّة:

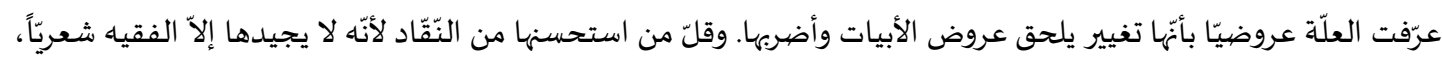

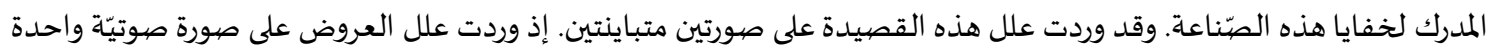

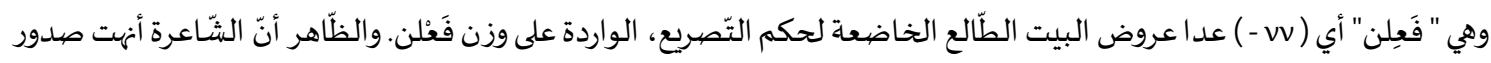

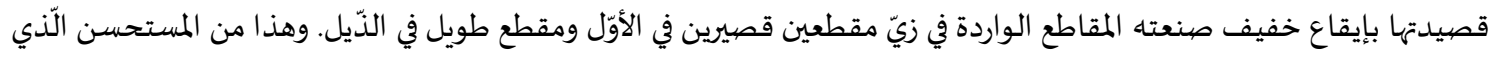

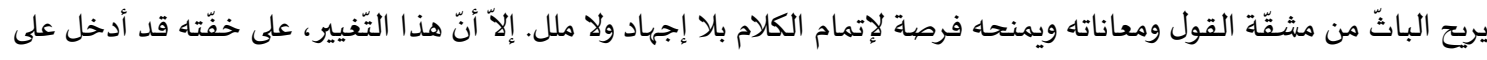

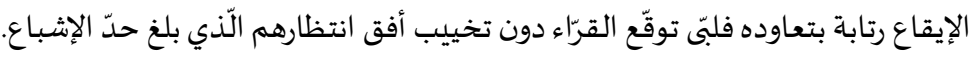

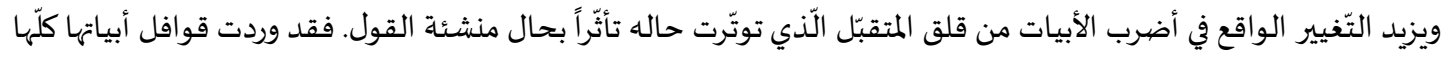

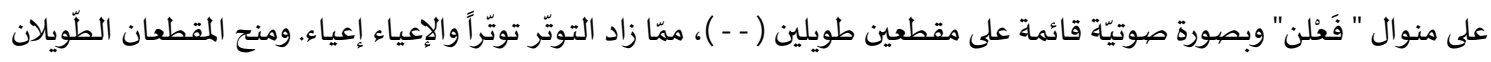

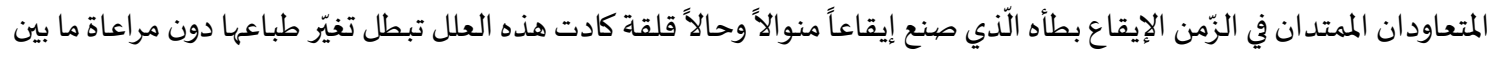

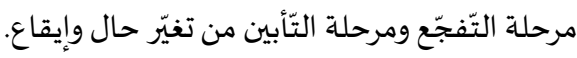

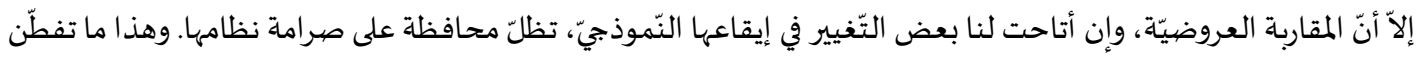

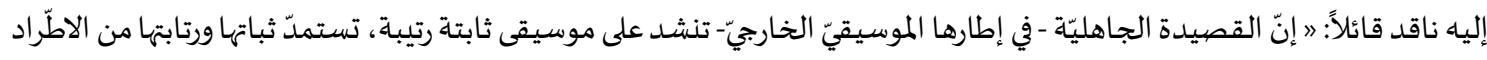

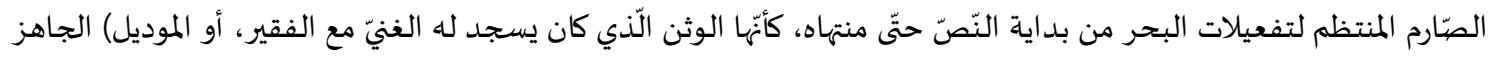




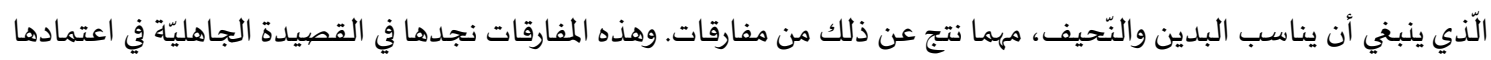

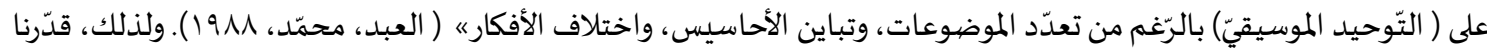

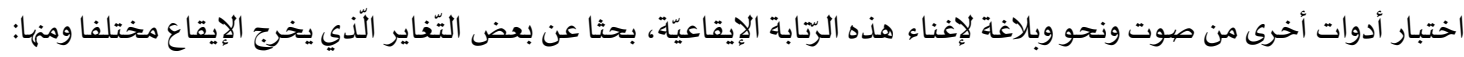

\section{إيقاعيّة الأصهوات المفردة:}

للصيّوت، مفردا أو داخل الكلمة، أهمّيّة سامقة في الكشف عن أسرار المعاني. وهذا سرّ اهتمام اللّغويّين بهاه من أمثال سيبويه

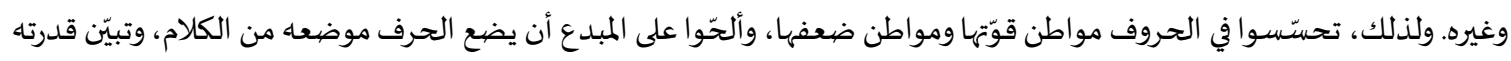

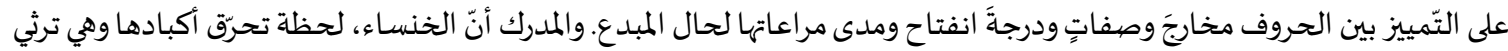

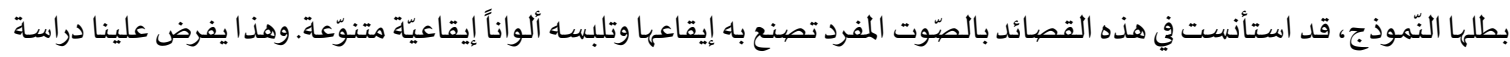

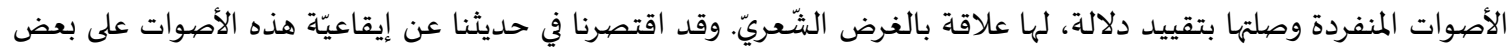

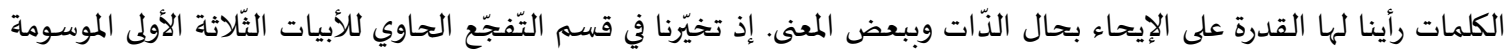

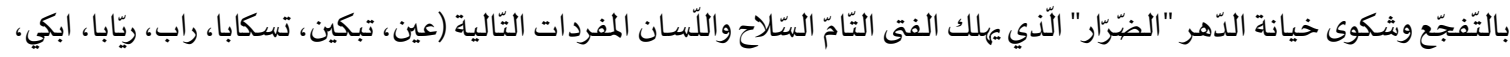

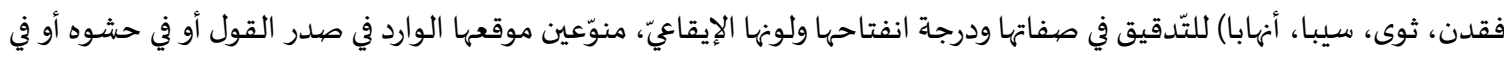
ذيله، ليكون المستنتج أقرب إلى بعض الوجاهيا.

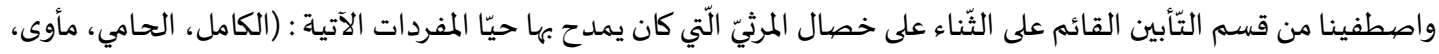

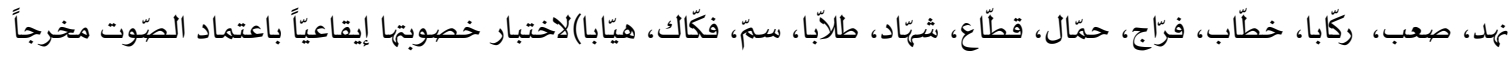

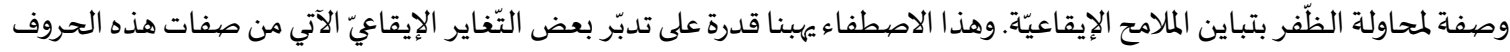

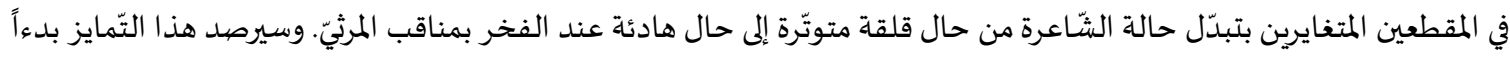

1. إيقاعيّة الأصوات المجهورة:

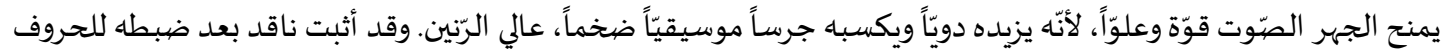

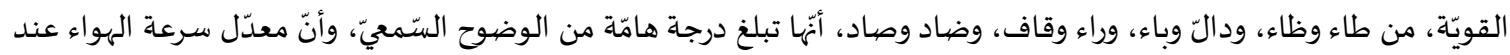

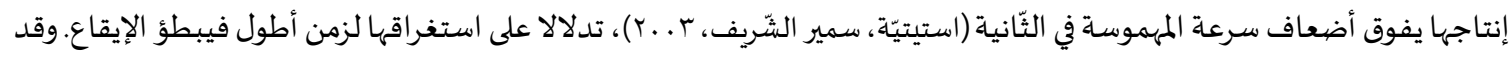

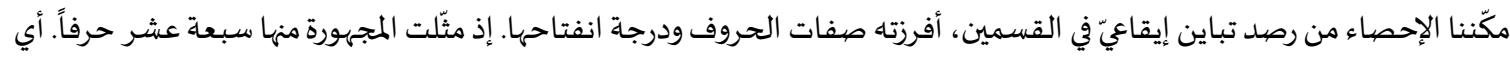

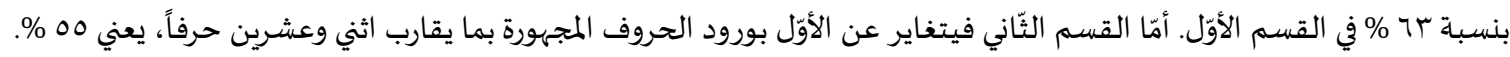

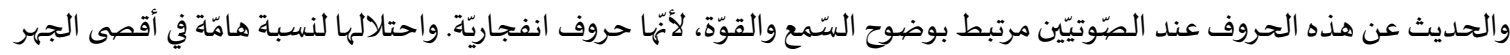

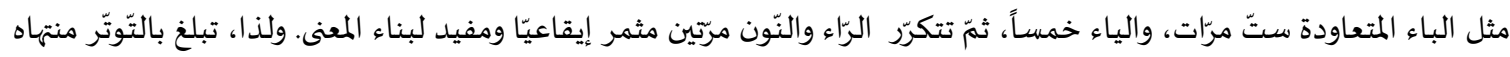

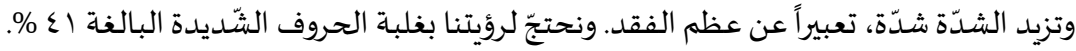

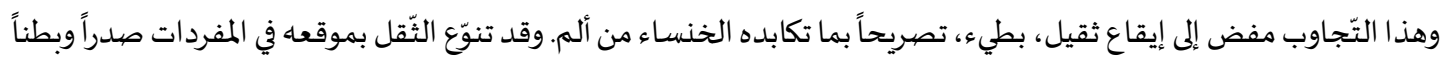

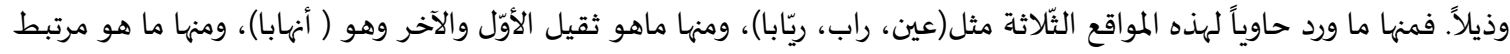

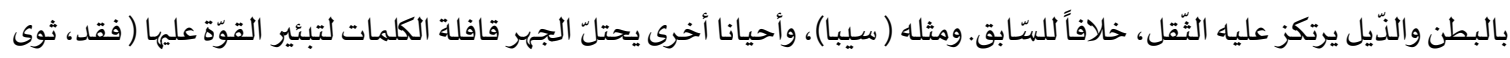

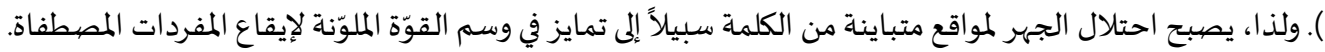

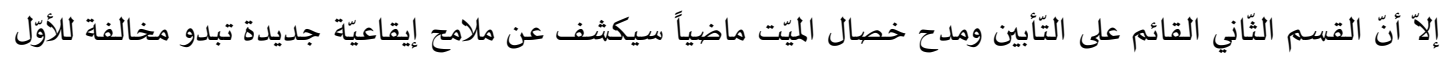

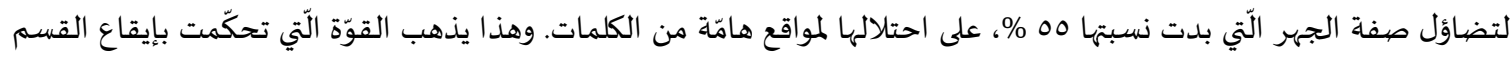

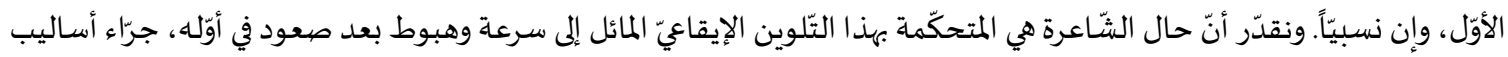

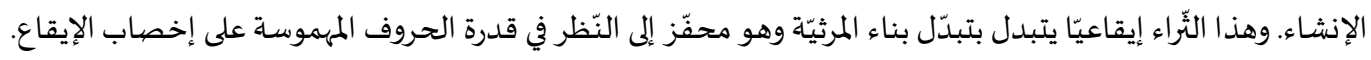

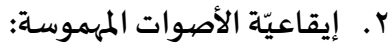

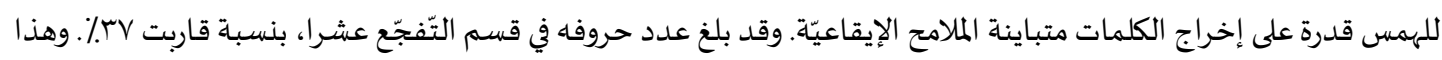

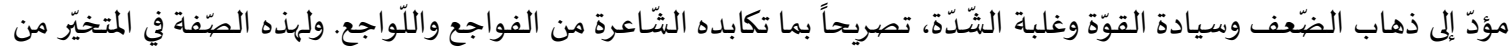

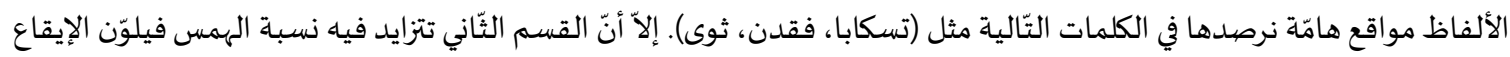

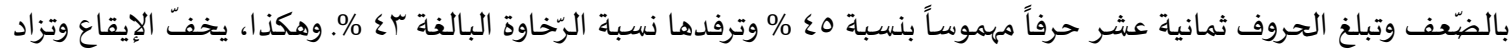




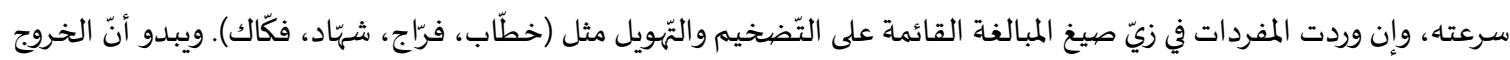

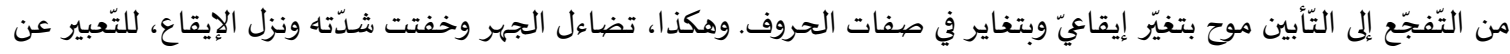

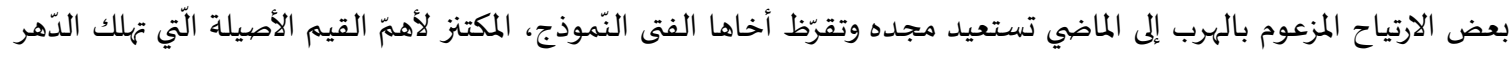

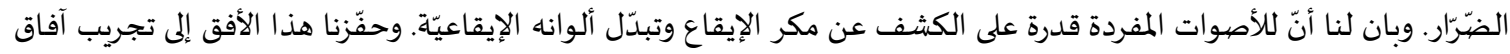

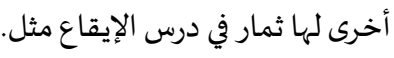

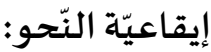

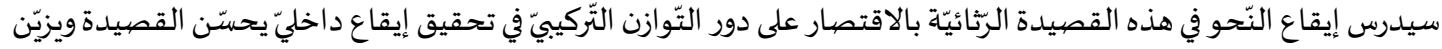

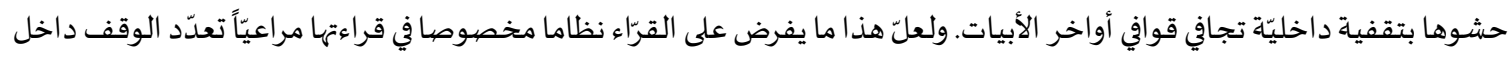

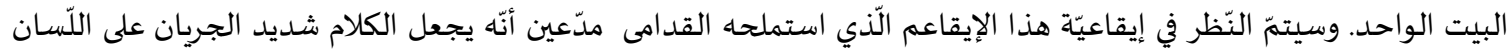

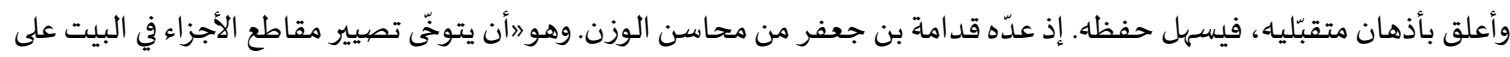

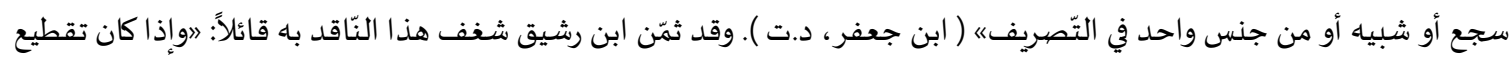

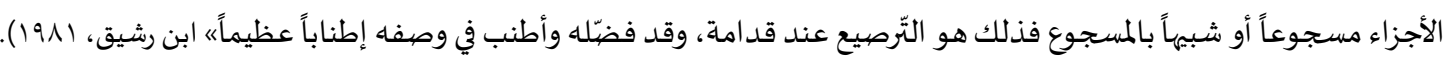

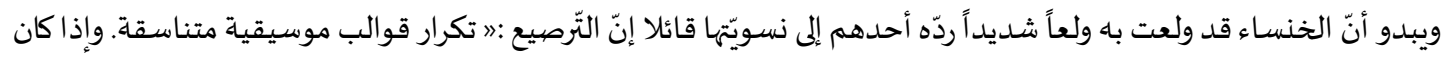

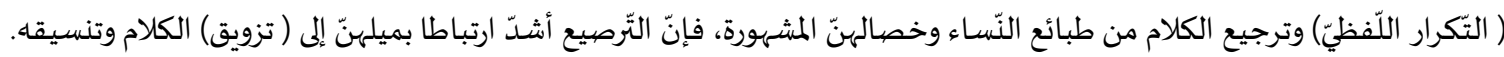

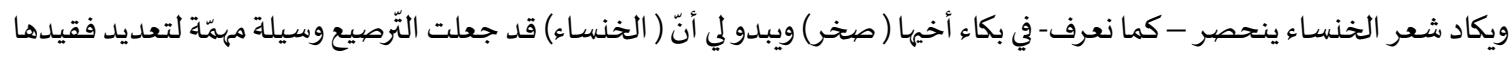

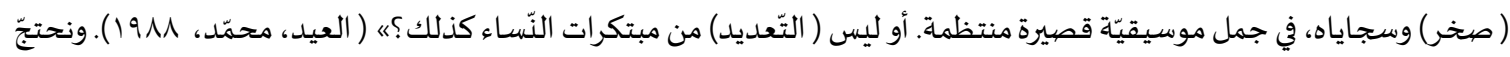

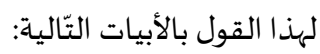

\begin{tabular}{|c|c|}
\hline والصيّدقُُ حوزتُك/ إن قرنُه هابًا & المججدُ حلَّتُه/ والجـودُ علتَتُه/ \\
\hline إن هاب معضلةً سَنَّى لها بَابًا & خطّابُ محفِلةٍة/ فرَّاجُ مظلمةٍِ/ \\
\hline شهّادُ أنجيدِ// للوتر طَلاِّبّا & حمّالُ ألويَة/ قطّاعُ أودية/ \\
\hline لاقَّ الوغَى لم يكن للموت هَيَّابًا & ل مِداة/وفكّاكُ العناة/ إذا \\
\hline
\end{tabular}

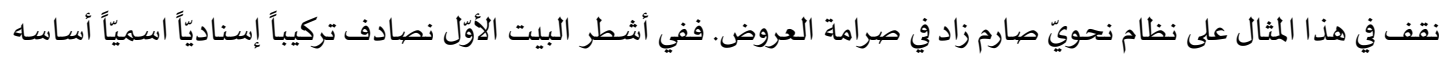

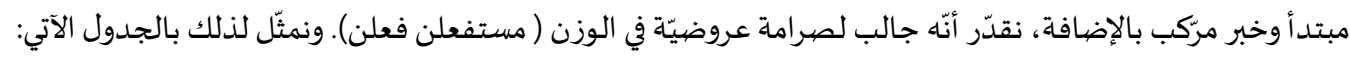

\begin{tabular}{|c|c|c|c|}
\hline وزنه العروضيّ & وسمه الإيقاعيّ & & المثثال \\
\hline مستفعلن فعلن & مبتدأ + خبر بالإضافة & (إيقاع صلب) & المجد حلَّهـ \\
\hline مستفعلن فعلن & \multicolumn{2}{|c|}{ مبتدأ + خبر بالإضافة ( إيقاع صلب) } & الجود علّتها \\
\hline مستفعلن فعلن & \multicolumn{2}{|c|}{ مبتدأ + خبر بالإضافة ( إيقاع صلب) } & الصيّدق حوزته \\
\hline
\end{tabular}

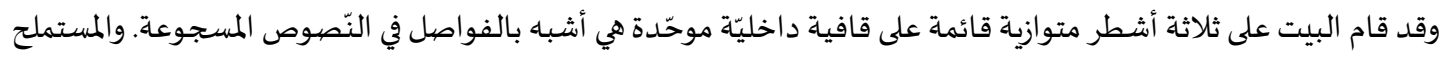

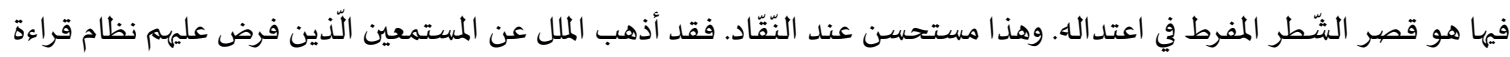

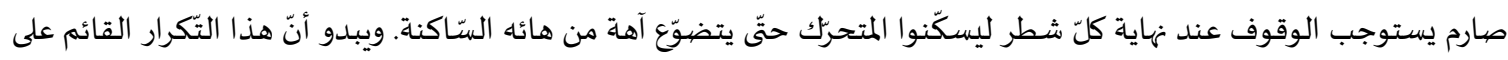

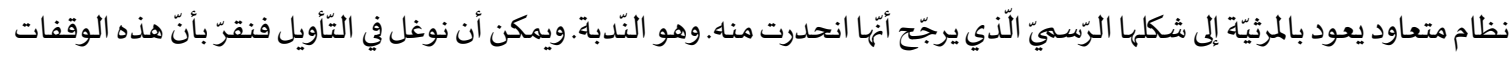

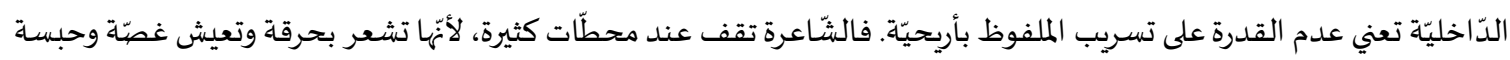

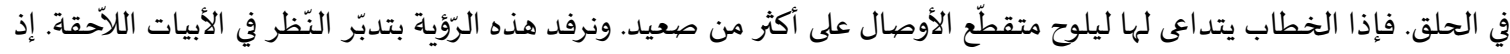

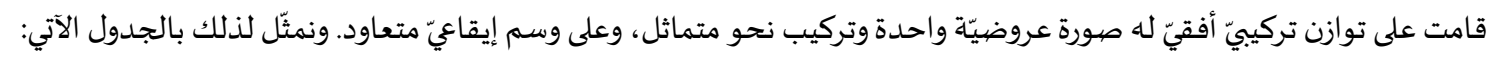

\begin{tabular}{|c|c|c|}
\hline 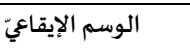 & 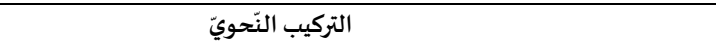 & 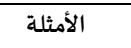 \\
\hline 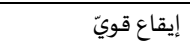 & مبتدأ محذذوف + خبر بالإضافة رأسه مضاف مشتقّ ( صيغة مبالغة على وزن فعَّال) & خطاّب محفلة \\
\hline 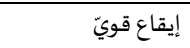 & مبتدأ محذذوف + خبر بالإضافة رأسه مضاف مشتقّ ( صيغة مبالغة على وزن فمّال) & 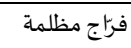 \\
\hline 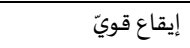 & مبتدأ محذذوف + خبر بالإضافة رأسه مضاف مشتقّ ( صيغة مبالغة على وزن فعَّال) & حمّال ألوية \\
\hline 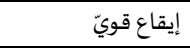 & مبتدأ محذذوف + خبر بالإضافة رأسه مضاف مشتقّ ( صيغة مبالغة على وزن فعَّال) & قطّاع أودية \\
\hline 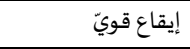 & مبتدأ محذوف + خبر بالإضافة رأسه مضاف مشتقّ ( صيغة مبالغة على وزن فعَّال) & 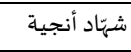 \\
\hline 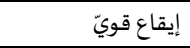 & مبتدأ محذوف + خبر بالإضافة رأسه مضاف مشتقّ ( صيغة مبالغة على وزن فعل) & 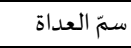 \\
\hline 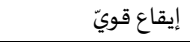 & مبتدأ محذذوف + خبر بالإضافة رأسه مضاف مشتقّ ( صيغة مبالغة على وزن فعًال) & 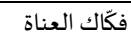 \\
\hline
\end{tabular}




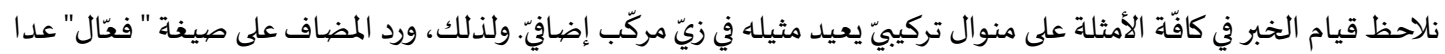

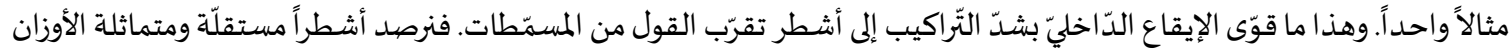

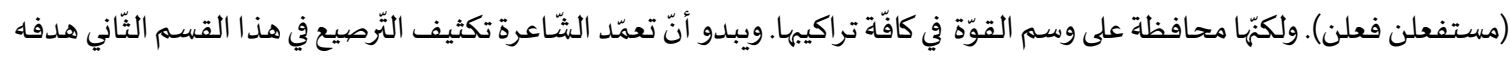

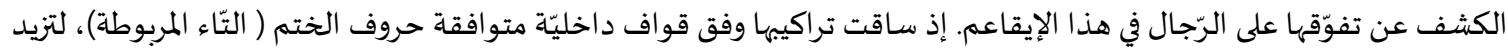

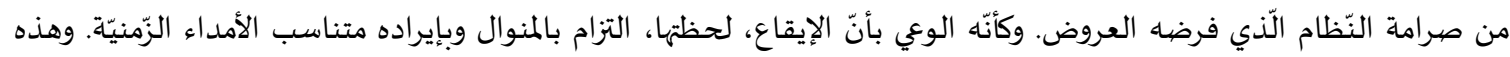

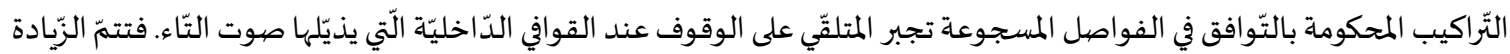

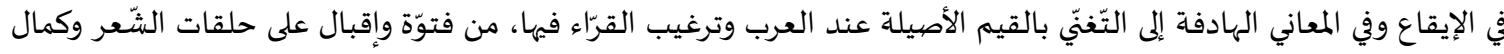

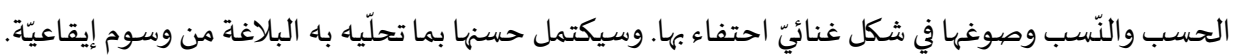

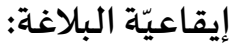

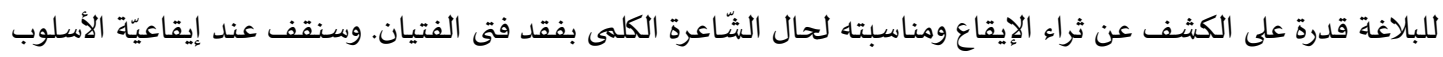

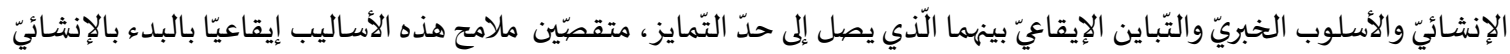

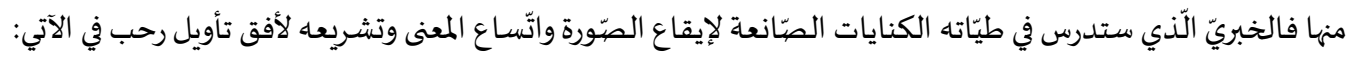

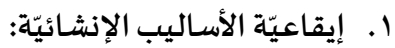

\begin{tabular}{|c|c|c|}
\hline الوسم الإيقاعيّ & الأسلوب & المثال \\
\hline إيقاع صاعد & نداء البعيد لبعده عن الوجدان & با عين \\
\hline إيقاع هابط & التّعجّبَ & ما لك لا تبكين \\
\hline إيقاع صاعد/ثقيل & الأمر & فابكي \\
\hline إيقاع صاعد/ ثقيل & الأمر & وابكي \\
\hline إيقاع صاعد/ ثقيل & الأمر & وابكي \\
\hline
\end{tabular}

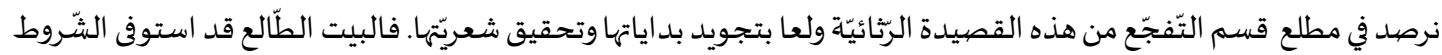

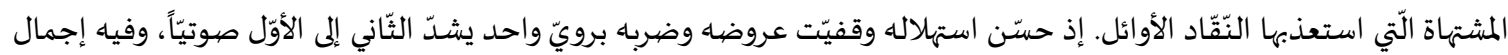

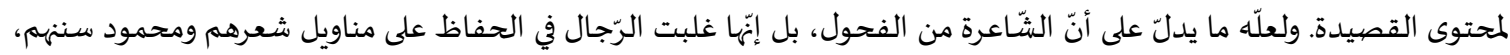

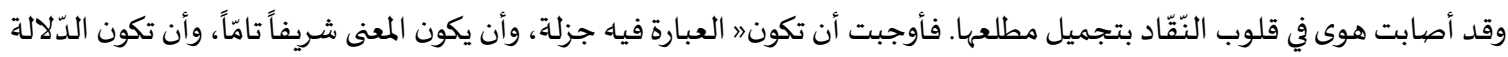

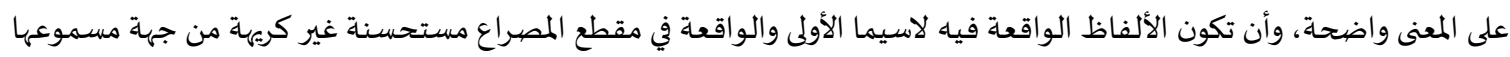

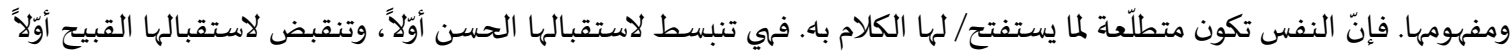

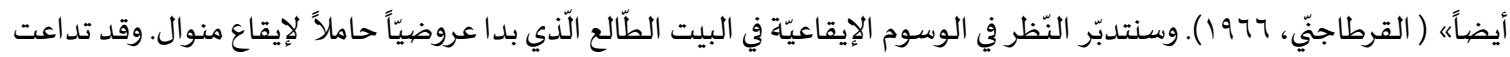

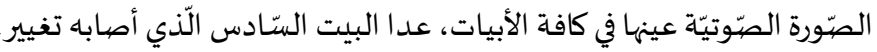

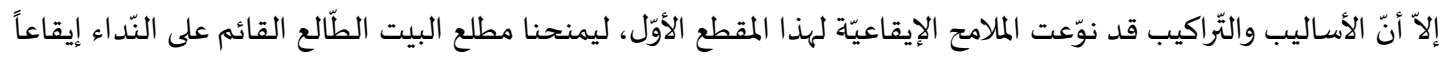

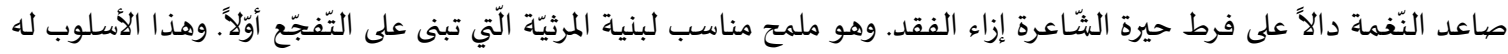

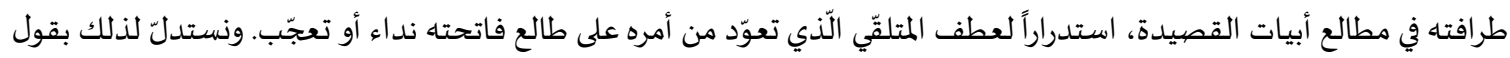

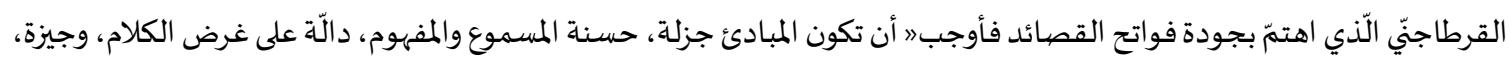

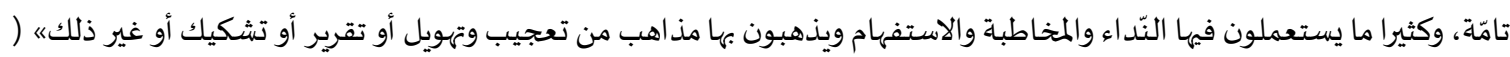

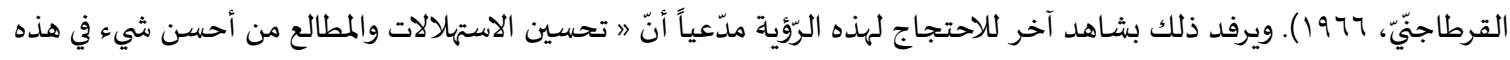

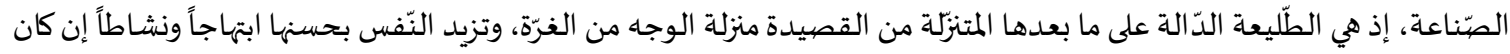

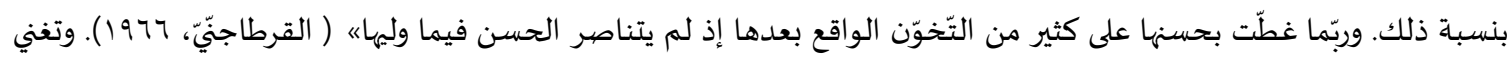

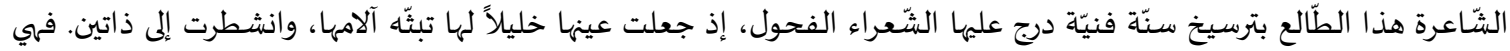

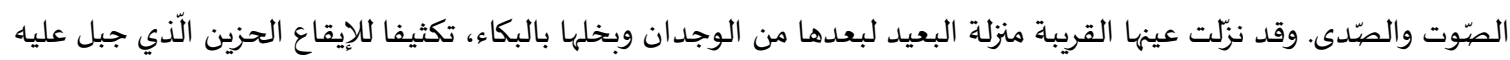

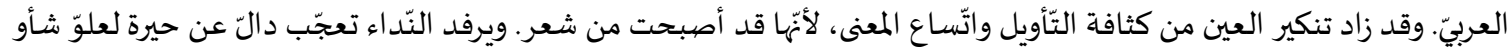

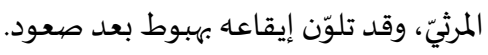

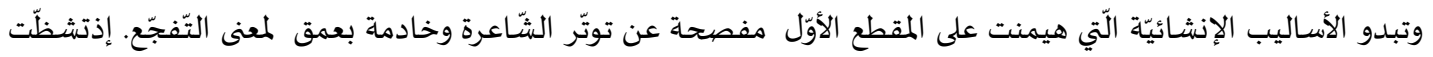




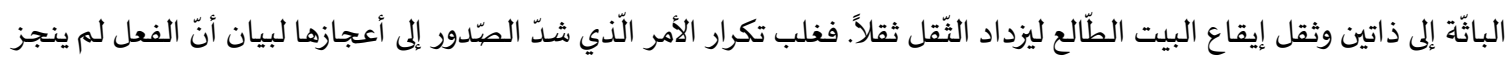

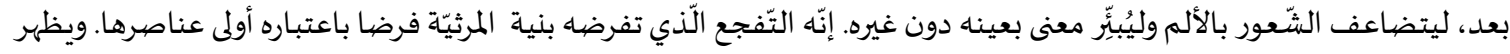

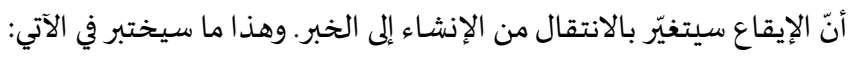

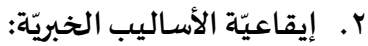

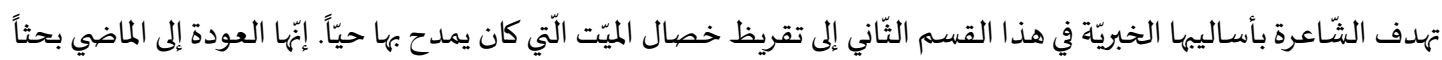

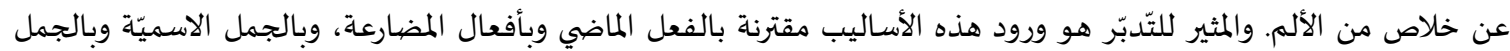
المحذوفة القائمة على الكناية. وسيتمّ تفصيل ذلك الك في لمن في الآتي:

\begin{tabular}{|c|c|c|}
\hline الوسم الإيقاعيّ & صورته & الخبر \\
\hline إيقاع خفّة & أسلوب خبري بفعل ماض & فقدن لما ثوى \\
\hline المراوحة بين الخفّة والثقل & أسلوب خبري بفعلين في المضارع & يعدو باه سابح/يهدي الرعيل \\
\hline إيقاع صلابة & أسلوب خبري بجمل اسميّة & حوزته حلَّته/ الجود علَّه/ الصَّدق \\
\hline إيقاع قويّ، فيه اتّساع المعنى. & أساليب خبريّة قائمة على الكناية & 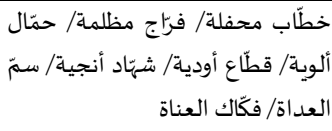 \\
\hline
\end{tabular}

نلاحظ أنّ أغلب الأساليب الخبريّة قد تغاير إيقاعها. فنجد فهيا ملمح الارتياح المزعوم الآتي من الفعل الماضي " فقدن"، وتراوح

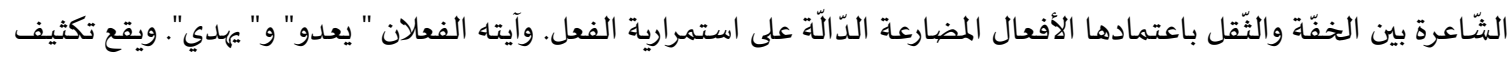

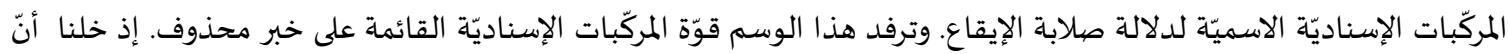

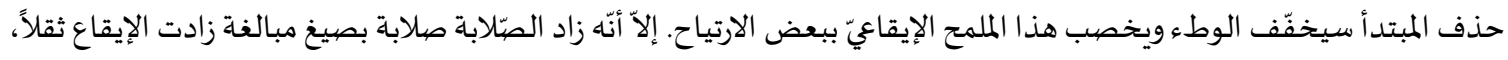

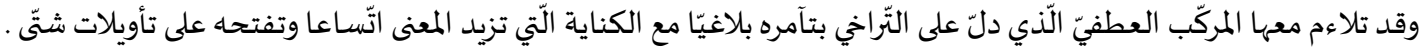

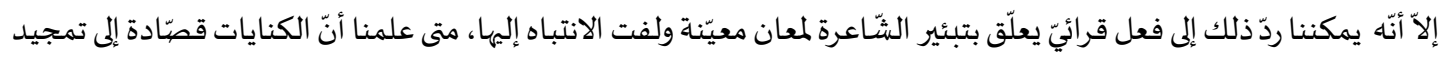

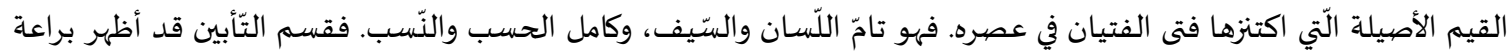

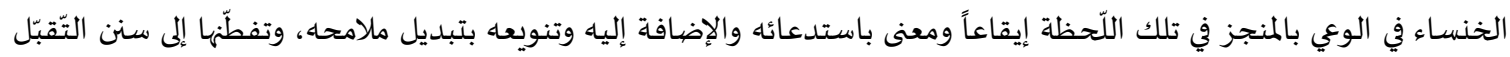

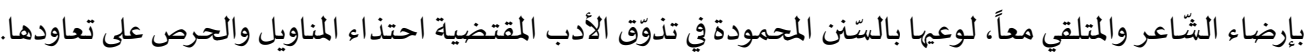

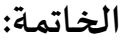

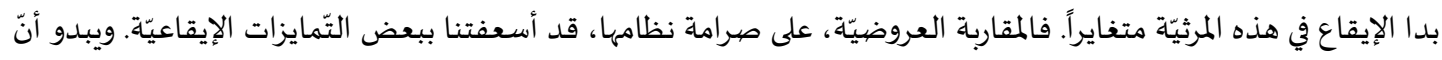

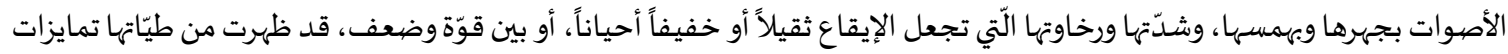

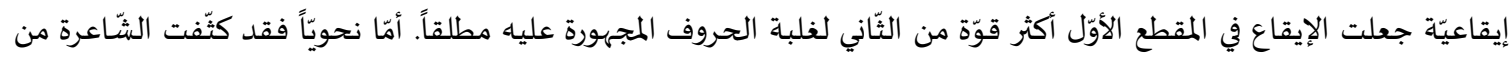

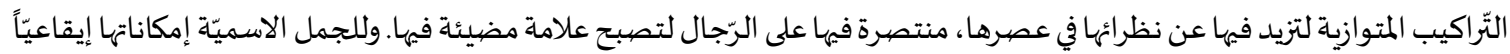

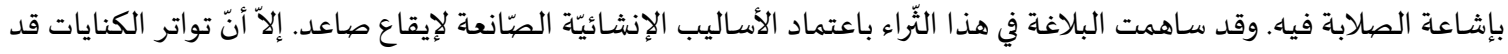

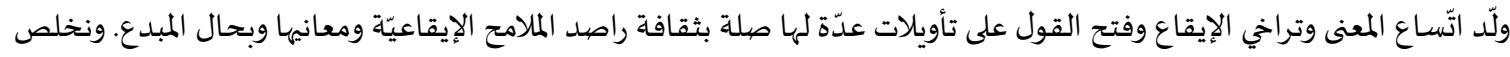

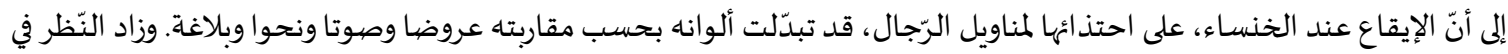

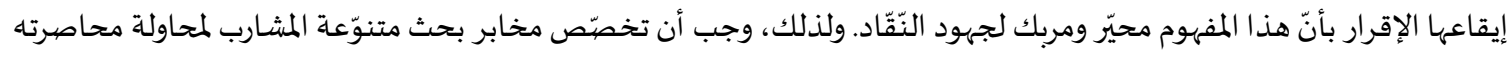

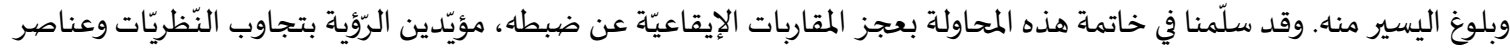
القول كافّها في تذليل صعوبات الظّفر به.

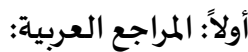

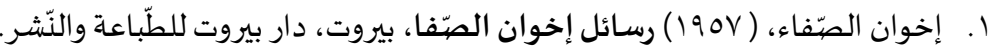

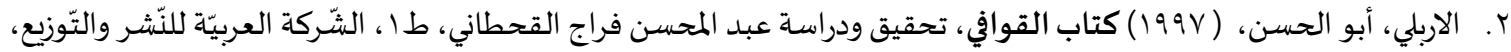




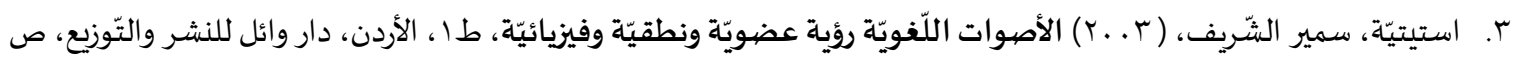

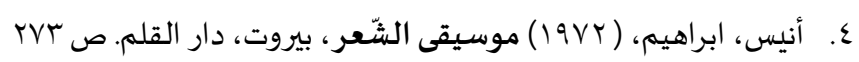

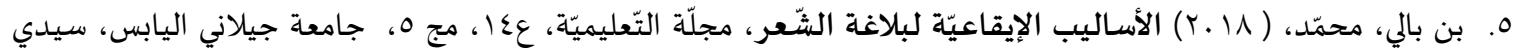

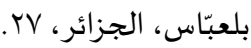

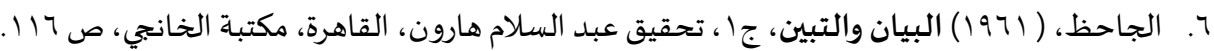

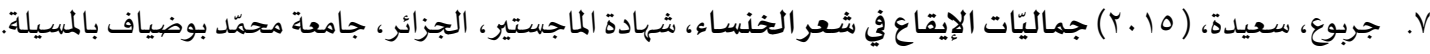

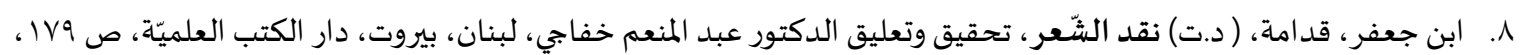

$\Lambda \cdot ص \cdot 1 \Lambda \cdot ص$

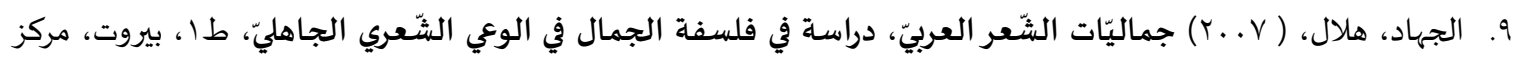

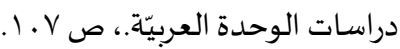

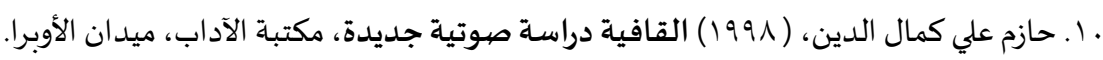

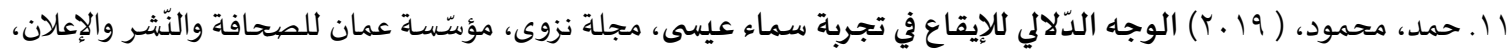

$1 \cdot \varepsilon$

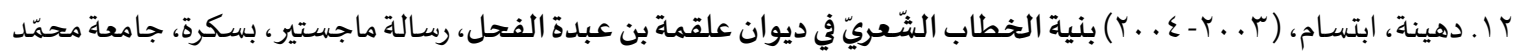

خيضر، ص

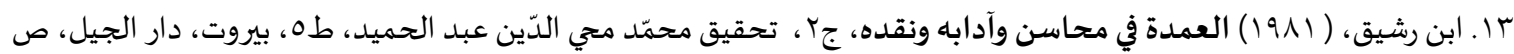

r

عا. الستجلماسي، أبو القاسم، (.91 (المنزع البديع في تجنيس أساليب البديع، تحقيق العلال غازي، الربّاط، مكتبة المعارف، ص

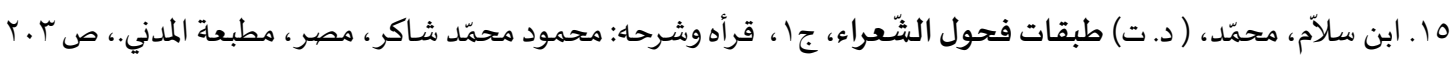

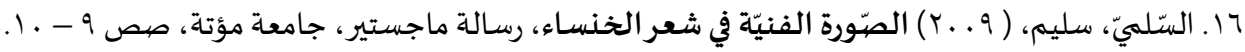

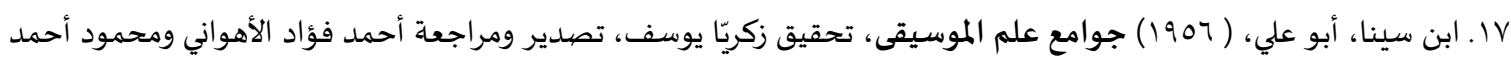
الحنفي، المطبعة الأميريّة بالقاهرة.

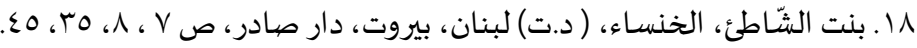

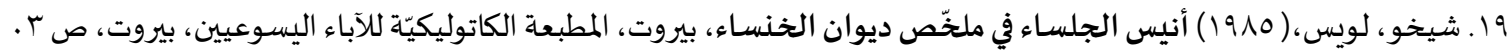

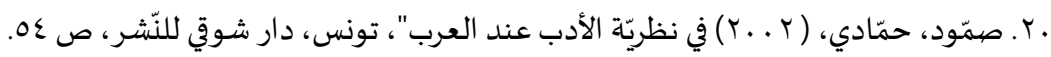

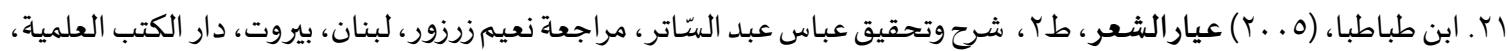
. $111-1 . r$

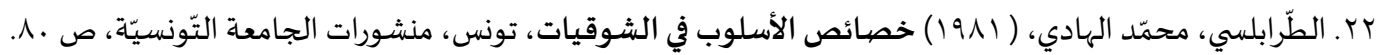

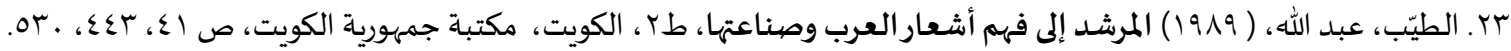

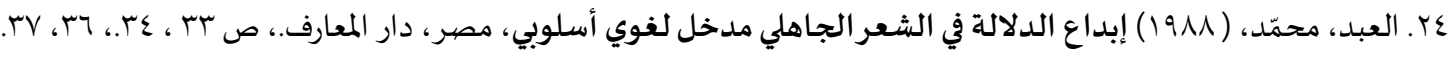

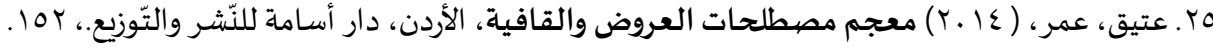

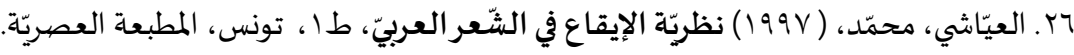

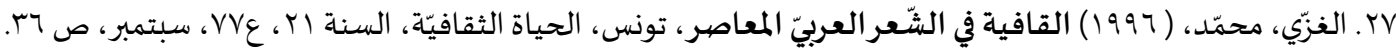

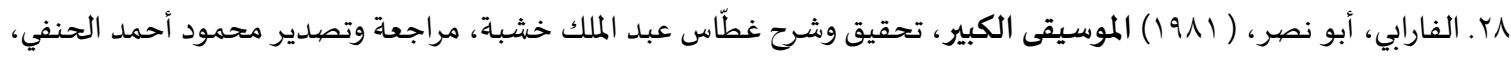

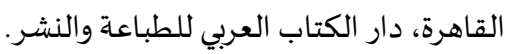

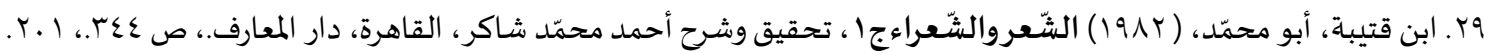

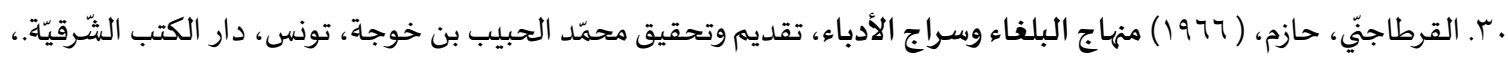

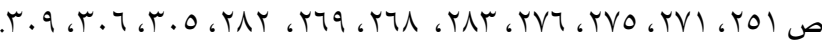

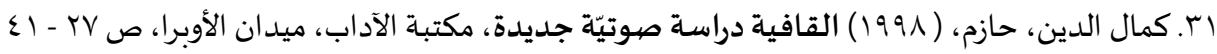


r r. الكنديّ، (r (97 ) مؤلّفات الكنديّ الموسيقيّة، تحقيق زكريّا يوسف، القاهرة، مطبعة شفيق. بr. المسعدي، محمود، (1997) الإيقاع في السجع العربي محاولة تحليل وتحديد، تونس، مؤسّسات عبد الكريم بن عبد الله.

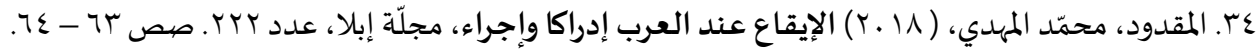

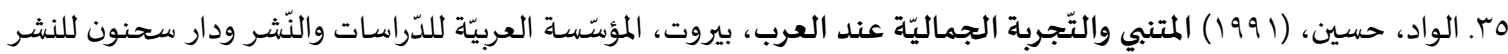

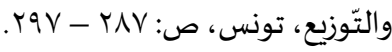

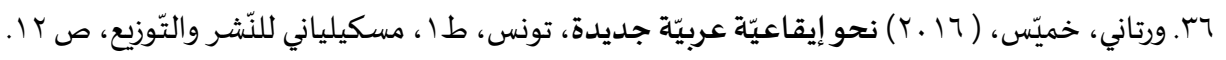
ثانياً: المراجع الأجنبية:

[1] Dessons. Gérard et Meschonnic, Henri, Traité du rythme des vers et des proses, Ed. Dunod, Paris, (1998).

[2] Jakobson. Roman, Huit questions de poétique, Editions du Seuil, Paris, (1977).

[3] Meschonnic. Henri, Critique du rythme, éd, Verdier, (1982). 
المجلة الدولية للدراسات اللغوية والأدبية العربية

International Journal for Arabic Linguistics and Literature Studies (JALLS)

www.refaad.com

Journal Homepage: https://www.refaad.com/views/JALS/home.aspx ISSN: 2663-5860(Online) 2663-5852(Print)

\title{
The Characteristics of Rhythm in Alkhansa's Poem
}

\author{
Mohamed Saleh Al- Hamraoui \\ Higher Institute of Humanities, University of Tunis Al-Manar, Tunis \\ mohamed.hamraoui.beja@gmail.com
}

Received Date : 9/5/2020

Accepted Date : 7/6/2020

DOI : https://doi.org/10.31559/JALLS2020.2.2.3

Abstract: In this paper, we shall focus on the characteristics of the rhythm in female poetry through Alkhansa's poem as a case study. We have theoretically defined this term through referring to ancient and modern philosophers and critics who have tackled this issue both in the Arab and Western world. Then, we have selected a few studies that we consider useful. We have selectively introduced the poetess in a way that serves our objectives by scrutinising critics 'view of her and their focus on her areas of excellence. Practically, we have examined the potential of the prosody approach, deeply entrenched in the model paradigm, to get the better of rhythm. Ellipsis and substitution allowed for some rhythmic variety. Grammar and rhetoric seem to have built a various rhythm, which reinforces the rhythmic paradigm. This has given us the impression that the distinctiveness of the rhythm of parallelism in Alkhansa's poetry has set her on top of a highly masculine school. We can safely advocate the masculinity of women and their good mastery of the model rhythm and their ability to deconstruct and enrich it by recurring to rhyming and oscillating between rising and falling tones on the one hand and various rhythms which combine strength and weakness and gain a deeper meaning from the use of metonymy. It seems that the oscillation between composition and discourse has revealed a link between rhythm and the speaker's state of mind whether it is calm or tense.

Keywords: Rhythm; Narrated; rhyme; section; beginning; Up tone; Flat tone, differentiation; Symmetry; Uniqueness; weight; lightness; Repetition; parallelism; The breadth of meaning.

\section{References:}

[1] Al'bd. Mhmd, Ebda'e Aldlalh Fy Alsh'r Aljahly Mdkhl Lghwy Aslwby, Msr, Dar Alm'arf., (1988), pp. 33, 34., 36, 37.

[2] 'tyq, 'mr, M'jm Mstlhat Al'rwd Walqafyh, Alardn, Dar Osamh Llnshr Waltwzy'., (2014), 152.

[3] Al'yashy. Mhmd, Nzryh Aleyqa' Fy Alsh'r Al'rby, T1, Twns, Almtb'h Al'sryh, (1997).

[4] Alarbly. Abw Alhsn, Ktab Alqwafy, Thqyq Wdrash 'bd Almhsn Fraj Alqhtany, T1, Alshrkh Al'rbyh Llnshr Waltwzy', 77, (1997).

[5] Anys. Abrahym, Mwsyqa Alsh'r, Byrwt, Dar Alqlm, (1972), pp. 273.

[6] Astytyh. Smyr Alshryf, Alaswat Allghwyh R'eyh 'dwyh Wntqyh Wfyzya'eyh, T1, Alardn, Dar Wa'l Llnshr Waltwzy', (2003), pp. 103.

[7] Bn Baly. Mhmd, Alasalyb Aleyqa'yh Lblaghh Alsh'r, Mjlt Alt'lymyh, '14, Mj 5, Jam't Jylany Alyabs, Sydy Bl'bas, Aljza'r, (2018), 27.

[8] Dessons. Gérard et Meschonnic, Henri, Traité du rythme des vers et des proses, Ed. Dunod, Paris, (1998).

[9] Dhynh.Abtsam, Bnyt Alkhtab Alsh'ry Fy Dywan 'lqmh Bn 'bdh Alfhl, Rsalt Majstyr, Bskrh, Jam't Mhmd Khydr, (2003- 2004), pp. 28. 
[10] Ekhwan Alsfa', Rsa'l Ekhwan Alsfa, Byrwt, Dar Byrwt Lltba'h Walnshr, (1957).

[11] Alfaraby. Abw Nsr, Almwsyqa Alkbyr, Thqyq Wshrh Ghtas 'bd Almlk Khshbh, Mraj'h Wtsdyr Mhmwd Ahmd Alhnfy, Alqahrh, Dar Alktab Al'rby Lltba'h Walnshr, (1981).

[12] Alghzy. Mhmd, Alqafyh Fy Alsh'r Al'rby Alm'asr, Twns, Alhyah Althqafyh, Alsnh 21, '77(1996), Sbtmbr, pp. 36.

[13] Hazm 'ly Kmal Aldyn, Alqafyh Drash Swtyh Jdydh, Mktbt Aladab, Mydan Alawbra, (1998).

[14] Hmd. Mhmwd, Alwjh Aldlaly Lleyqa' Fy Tjrbt Sma' 'ysa, Mjlt Nzwa, M'sst 'man Llshafh Walnshr Wale'lan, '100, (2019).

[15] Abn J'fr. Qdamh, Nqd Alsh'r, Thqyq Wt'lyq Aldktwr 'bd Almn'm Khfajy, Lbnan, Byrwt, Dar Alktb Al'lmyh, pp. 179, 180, 80.

[16] Aljahz, Albyan Waltbyn, J1, Thqyq 'bd Alslam Harwn, Alqahrh, Mktbt Alkhanjy, (1961), pp. 116.

[17] Jakobson. Roman, Huit questions de poétique, Editions du Seuil, Paris, (1977).

[18] Aljhad. Hlal, Jmalyat Alsh'r Al'rby, Drash Fy Flsft Aljmal Fy Alw'y Alsh'ry Aljahly, T1, Byrwt, Mrkz Drasat Alwhdh Al'rbyh, (2007), pp.107.

[19] Jrbw'. S'ydh, Jmalyat Aleyqa' Fy Sh'r Alkhnsa', Shhadt Almajstyr, Aljza'r, Jam't Mhmd Bwdyaf Balmsylh, (2015).

[20] Kmal Aldyn. Hazm, Alqafyh Drash Swtyh Jdydh, Mktbh Aladab, Mydan Alawbra, (1998), pp. 2741.

[21] Alkndy, M'lfat Alkndy Almwsyqyh, Thqyq Zkrya Ywsf, Alqahrh, Mtb't Shfyq, (1962).

[22] Meschonnic. Henri, Critique du rythme, éd, Verdier, (1982).

[23] Almqdwd, Mhmd Almhdy, Aleyqa' 'nd Al'rb Edraka Wejra', Mjlt Ebla, 'dd 222(2018), pp. 63- 64.

[24] Alms'dy. Mhmwd, Aleyqa' Fy Alsj' Al'rby Mhawlt Thlyl Wthdyd, Twns, M'ssat 'bd Alkrym Bn 'bd Allh, (1996).

[25] Alqrtajny. Hazm, Mnhaj Alblgha' Wsraj Aladba', Tqdym Wthqyq Mhmd Alhbyb Bn Khwjh, Twns, Dar Alktb Alshrqyh., (1966), pp. 251, 271, 275, 276, 283, 268, 269, 282, 305, 306, 309.

[26] Abn Qtybh.Abw Mhmd, Alsh'r Walsh'ra'j1, Thqyq Wshrh Ahmd Mhmd Shakr, Alqahrh, Dar Alm'arf., (1982), pp. 344, 201.

[27] Abn Rshyq, Al'mdh Fy Mhasn Wadabh Wnqdh, J2, Thqyq Mhmd Mhy Aldyn 'bd Alhmyd, T5, Byrwt, Dar Aljyl, (1981), pp. 26.

[28] Bnt Alshat'. Alkhnsa', Lbnan, Byrwt, Dar Sadr, pp. 7, 8, 35, 45.

[29] Shykhw. Lwys, Anys Aljlsa' Fy Mlkhs Dywan Alkhnsa', Byrwt, Almtb'h Alkatwlykyh Llaba' Alysw'yyn, Byrwt, (1985), pp. 3.

[30] Alsjlmasy. Abw Alqasm, Almnz' Albdy' Fy Tjnys Asalyb Albdy', Thqyq Al'lal Ghazy, Alrbat, Mktbt Alm'arf, (1980), pp. 407.

[31] Abn Slam. Mhmd, Tbqat Fhwl Alsh'ra', J1, Qrah Wshrhh: Mhmwd Mhmd Shakr, Msr, Mtb't Almdny., pp. 203.

[32] Alslmy. Slym, Alswrh Alfnyh Fy Sh'er Alkhnsa', Rsalt Majstyr, Jam't M'th, (2009), pp 9- 10.

[33] Smwd. Hmady, Fy Nzryh Aladb 'nd Al'rb", Twns, Dar Shwqy Llnshr, (2002), pp. 54.

[34] Abn Syna. Abw 'ly, Jwam'e 'Im Almwsyqa, Thqyq Zkrya Ywsf, Tsdyr Wmraj't Ahmd F'ad Alahwany Wmhmwd Ahmd Alhnfy, Almtb'h Alamyryh Balqahrh, (1956). 
[35] Abn Tbatba, 'yar Alsh'r, T2, Shrh Wthqyq 'bas 'bd Alsatr, Mraj't N'ym Zrzwr, Lbnan, Byrwt, Dar Alktb Al'lmyh, (2005), pp. 21., 102 - 111.

[36] Altrablsy. Mhmd Alhady, Khsa's Alaslwb Fy Alshwqyat, Twns, Mnshwrat Aljam'h Altwnsyh, (1981), pp. 80.

[37] Altyb. 'bd Allh, Almrshd Ela Fhm Ash'ar Al'rb Wsna'tha, T2, Alkwyt, Mktbt Jmhwryh Alkwyt, (1989), pp. 41, 443, 530 .

[38] Alwad, Hsyn, (1991) Almtnby Waltjrbh Aljmalyh 'End Al'erb, Byrwt, Alm'essh Al'erbyh Lldrasat Walnshr Wdar Shnwn Llnshr Waltwzy'e, Twns, S: 287 - 297 .

[39] Wrtany, Khmys, (2016) Nhw Eyqa'eyh 'Erbyh Jdydh, Twns, T1, Mskylyany Llnshr Waltwzy'e, S 12. 